\title{
Effect of a Uniform Partial Denervation of the Periphery on the Peripheral and Central Vibrissal System in Guinea Pigs
}

\author{
Linmarie Sikich, ${ }^{*}$ Thomas A. Woolsey, $\dagger$ and Eugene M. Johnson, Jr. $\ddagger$

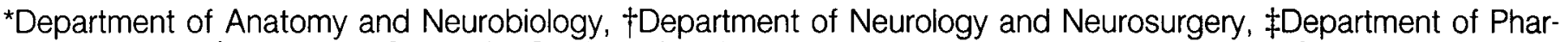 \\ macology, and TMcDonnell Center for Studies of Higher Brain Function, Washington University School of Medicine, \\ Saint Louis, Missouri 63110
}

In some rodents, somatotopically organized architectonic patterns corresponding precisely to the arrangement of the vibrissae on the face are found in each of the central stations of the trigeminal (V) pathway. Two lines of evidence indicate that these architectonic patterns reflect the level of peripheral innervation. First, in normal mice, the sizes of the individual units within the cortical representation are proportional to the number of fibers supplying the corresponding vibrissal follicles. Second, complete surgical denervation of groups of vibrissae can severely attenuate the sizes of and alter the patterns of their central representations. However, previous studies in this system do not distinguish the effects of the absolute and the relative levels of peripheral innervation on central representations. To address this question, we have studied guinea pigs in which all vibrissae are partially deafferentated before birth by fetal exposure to antibodies against NGF. This approach reduces the absolute level of peripheral innervation in a graded way, and does so uniformly, without changing the pattern of vibrissal innervation.

In the most severely affected animals, only $18 \%$ of the normal number of $V$ ganglion neurons survive. The effect of this loss on the $V$ system was assessed by comparing the peripheral and central components of the vibrissal system in normal and NGFdeprived animals. Peripheral fibers from the $V$ ganglion neurons, including those to the vibrissae, are less reduced in number $(50 \%)$ than expected. The number of peripheral fiber fascicles is also decreased. In contrast, neither the patterns nor the areas of the central representations in medulla and cortex differ from those of normal animals. We conclude that (1) $18 \%$ of the normal number of $\mathrm{V}$ ganglion cells is sufficient to establish normal central architectonic patterns and (2) the size of the central vibrissal representations is independent of the absolute magnitude of peripheral innervation. These observations are of relevance to understanding the role of NGF on the morphogenesis of central somatosensory pathways, the effects of "mismatches" between peripheral innervation, and the development of projec-

\footnotetext{
Received Mar. 15, 1985; revised Oct. 28, 1985; accepted Oct. 30, 1985.

This paper is dedicated to our colleague Viktor Hamburger. We thank him for his helpful suggestions as the study progressed and his comments on the manuscript. This work was supported by NIH Grants NS17763, NS18071, and 5T32NS0757 and by the McKnight Foundation. We very much appreciate Patricia Osborne's excellent preparation and care of the NGF-deprived animals and her sound advice concerning them. We are grateful to PoKay Ma for his technical advice throughout the course of this study. We also thank Richard Cheney, Dr. Diane Tucker, and Dr. Henry Yip for criticisms of the manuscript. Finally, we wish to thank Nhan van Hoang for his patience and skilled histology, Dr. Mike Dierker for help with computer analysis of the quantitative data, Bob Freund, Monica Herk, and Joe Hayes for help with the photography, and Margo Gross for secretarial assistance. Dr. Dianne Durham prepared some of these materials.

Correspondence should be addressed to Dr. Woolsey, Department of Neurosurgery, Box 8057, Washington University School of Medicine, 660 South Euclid Avenue, Saint Louis, MO 63111.
}

Copyright @ 1986 Society for Neuroscience $0270-6474 / 86 / 051227-14 \$ 02.00 / 0$ tions to central targets in the mammalian brain, and provide new data for understanding competitive interactions in the developing central and peripheral trigeminal system.

Understanding how peripheral structures come to be represented in a stereotyped topographic fashion within the CNS remains one of the fundamental goals of developmental neurobiology. The trigeminal system of some mammals has proved especially attractive for studies of this process because the representation of each whisker can be uniquely demonstrated histologically and physiologically throughout the CNS. The vibrissal pathway is represented schematically in Figure 1. Neurons located in the $\mathrm{V}$ ganglion send peripheral processes to the whiskers (vibrissae) via the infraorbital nerve (ION). Their central processes synapse in the ipsilateral brain-stem trigeminal complex, which has four subnuclei: pars principalis ( $\mathrm{nVp}$ ), pars oralis $(\mathrm{nVo})$, pars interpolaris ( $\mathrm{nVi}$ ), and pars caudalis $(\mathrm{nVc})$. The second-order neurons in the brain-stem trigeminal nuclei project to the contralateral ventrobasal (VB) complex of the thalamus. The third-order thalamic neurons then project to somatosensory (SmI) cortex.

In many rodents, including guinea pigs, Nissl stains demonstrate multicellular units resembling "barrels" within each of the central V stations, which are homeomorphic to the patterns of vibrissae on the face (Ma and Woolsey, 1984; Van der Loos, 1976; Woolsey and Van der Loos, 1970; Woolsey et al., 1975; and P. K. M. Ma, personal communication). These homeomorphic patterns can also be demonstrated with histochemical stains for mitochondrial enzymes at each level of the pathway (Belford and Killackey, 1979; Ma and Woolsey, 1984; WongRilcy and Welt, 1980) or by retrograde and anterograde transport techniques (e.g., Arvidsson, 1982; Ivy and Killackey, 1982; Jacquin and Rhoades, 1983; Woolsey, 1978). Electrophysiological recordings in rats and mice reveal functional organization consistent with the one-to-one correspondence between each vibrissa and each architectonic unit in the pattern of the anatomical representations in the cortex (Simons, 1978; Simons and Woolsey, 1979; Welker, 1976) and in the thalamus (Emmers, 1965; Verley and Onnen, 1981; Waite, 1973). In the cortex of normal mice, the cross-sectional area of each barrel is directly proportional to the number of cells comprising it, which in turn is directly proportional to the number of myelinated and unmyelinated axons innervating the corresponding vibrissal follicle (Lee and Woolsey, 1975; Woolsey and Dierker, 1982). Thus, both the position and the innervation density of each whisker appear to be reflected in its central representations.

In numerous studies of mice and of rats, the vibrissal pad has been deafferentated by electrocautery or transection of the peripheral fibers innervating the whisker follicles. If surgical destruction of the vibrissal nerves occurs sufficiently early in neonatal life, the central vibrissal representations are altered. These 
Figure 1. Schematic drawings of the vibrissal pathway and of the arrangement and nomenclature of the vibrissae on the face and their central representations in the brain-stem trigeminal nucleus pars interpolaris $(n V i)$ and the cortex in guinea pigs. $a$, Organization of the vibrissal sensory pathway. Refer to the text for details. $b$, Arrangement of the whiskers on the left face. There are six rows of whiskers designated $A$ $F$ in a dorsal to ventral direction; each row contains four whiskers, except for $B$, which has three, and $F$, which has five. Whisker B-3 is indicated by the asterisk, whisker $\mathrm{F}-3$ by the diamond. These peripheral receptor organs can be a face trigeminal nerve medulla: thalamus cortex

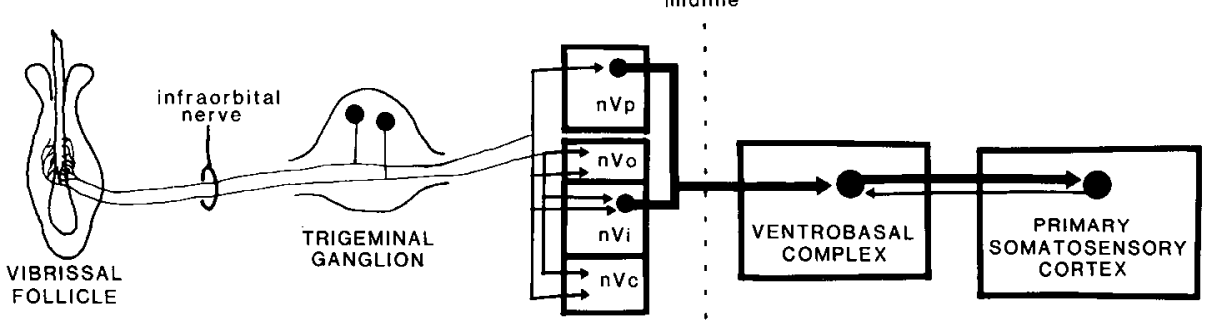
uniquely identified in each animal. Dorsal is up and rostral is to the left. $c$, Pattern of the whisker representation in the left $\mathrm{nVi}$. The arrangement is homeomorphic to that on the face except that the rows, which abut the trigeminal tract, appear more uniform than those on the face. The representation of B-3 is marked by the asterisk, that of F-3 by the diamond. Dorsal is up and lateral is to the left. $d$, Arrangement of the vibrissal representation within the right primary somatosensory cortex. The B-3 representation is marked by the asterisk, the F-3 representation by the diamond. Anterior is up and medial is to the left.

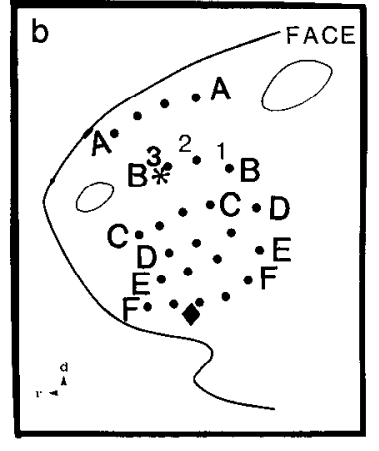

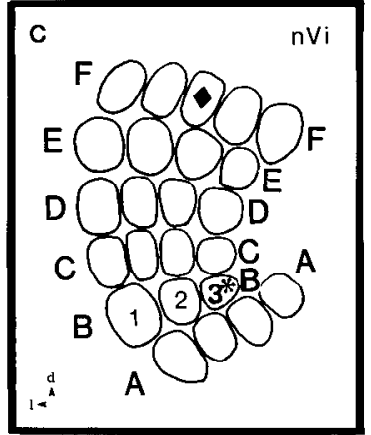

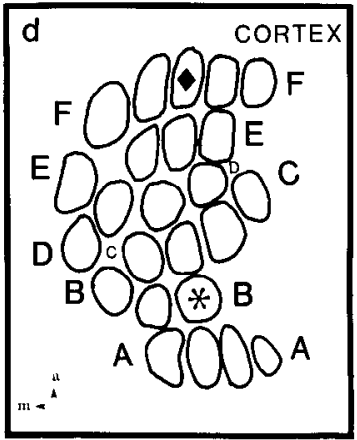

alterations reflect the changes in the peripheral innervation precisely (i.e., Kaas et al., 1983; Woolsey, 1984; Woolsey et al., 1981). They are not a rearrangement of existing cortical architecture, but are present from the time that cortical architectonic patterns first appear (Jeanmonod et al., 1977). For instance, if a single row of vibrissae is denervated during the appropriate critical period, the territories occupied by the thalamic and the cortical representations of the lesioned row decrease in size while the territories associated with the adjacent, uninjured rows increase in size. In the medulla, similar changes in the size of vibrissal representations have been reported in hamsters (Rhoades et al., 1983) but are much less pronounced or absent in mice and rats (Belford and Killackey, 1980; Durham and Woolsey, 1984). Functional results correspond to these anatomical alterations (Pidoux et al., 1979; Simons et al., 1984; Waite and Taylor, 1978).

After denervation of all the vibrissae, ION section or crush, the central patterns are altered such that in the most extreme cases homogeneous arrays of fibers and cells are seen and whisker-related architectonic patterns cannot be discerned (Woolsey et al., 1981). In rats in which the ION was crushed at birth, (Waite and Cragg, 1982), a cortical architectonic pattern was absent even though $30 \%$ of the ION fibers appeared to regenerate before the end of the cortical critical period. The finding raises the possibility that a threshold of peripheral innervation greater than $30 \%$ of the normal level is required to establish central architectonic patterns. Complete testing of this threshold hypothesis would require a system in which the innervation of the periphery could be reduced significantly in a graded way before central pattern formation begins.

The correspondence between the amount of whisker innervation and the size of the central vibrissal representations could be the result of two distinct developmental strategies. One would be to allocate central territory in direct proportion to the absolute magnitude of the innervation to each vibrissal follicle. A second strategy would be to divide all available central territory based on the relative innervation density of each follicle. None of the experimental methods utilized in previous studies distinguishes between these two possibilities. Separation of these developmental strategies should be possible if shifts in the relative levels of innervation could be eliminated while changing the absolute magnitude of peripheral innervation.

Recently, experimental animals in which this question can be addressed have become available. In some species, in utero exposure to maternal antibodies against the physiological trophic agent NGF results in a substantial loss of sympathetic and neural crest-derived sensory neurons. Within the species examined (rabbits, rats, and guinea pigs), guinea pigs show the greatest sensory neuron loss (Gorin and Johnson, 1979; Johnson et al., 1980, 1982; Pearson et al., 1983). This appears to be because (1) guinea pigs mount strongcr immunologic responses against their own NGF after immunization with mouse NGF (Johnson et al., 1983), and (2) maternal antibodies are present in the fetal circulation in higher concentrations earlier in development and for a longer period in guinea pigs than in the other species (Brambell, 1970). An alternative means of producing a generalized sensory denervation is neonatal treatment with capsaicin. Systemic exposure to this toxin early in postnatal development destroys a subset of unmyelinated $C$ fibers and their somata that transmit poorly localized pain (e.g., Nagy et al., 1980).

For purposes of this study, in utero NGF deprivation has significant advantages. First, because neurons die earlier in development, earlier events can be examined. Second, more neurons die than with capsaicin treatment. Finally, a heterogenous population of ganglion cells is lost, and the role of a generalized denervation rather than that of a smaller subset of neurons on pattern formation can be determined. The autoimmune approach is not very effective in the species-mice and rats-in which the vibrissa-barrel systems have been most fully char- 
acterized. This limitation can be overcome since the pattern of guinea pig vibrissae and their cortical representations have been partially described (Woolsey et al., 1975).

In spite of the value of the autoimmune model, the number of guinea pig offspring with profound sensory ganglion cell loss that can be generated is small. These animals survive at most for several days before they succumb to the complications of their neurological deficit. This paper reports a detailed morphological study of the trigeminal system with quantitative evaluation of various components of the pathway in normal and NGF-deprived guinea pigs. The organization of the guinea pig trigeminal pathway was determined first. Newborn control and experimental animals were evaluated clinically for somatosensory and nociceptive responses. The animals were prepared for light microscopy and counts of axons related to selected vibrissae, axons in the infraorbital nerve, and of cells in the trigeminal ganglion made. Central whisker projection patterns in the brain stem and cerebral cortex were reconstructed and measured. By comparing these values from a number of control and experimental animals, we have been able to characterize the anatomical changes, if any, in critical portions of this pathway as a consequence of in utero NGF deprivation. The results are both unexpected and interesting with respect to the questions outlined above and provide a substantial data base for further experimental evaluation of these rare but very interesting animals.

\section{Materials and Methods}

\section{Animals}

Hartley strain albino guinea pigs of both sexes were used. Animals weighing 80-100 gm were killed either on the first or second postnatal day (PND 1 or PND 2). Ten normal animals (from Issacs Lab Stock, Litchfield, IL) were examined histologically. The brains of five animals were stained to reveal Nissl substance and those of five animals for the mitochondrial enzyme succinic acid dehydrogenase (SDH). A total of 11 animals born to female guinea pigs immunized with mouse NGF (dams supplied by Charles River, Willmington, MA), 6 of which were severely affected (see below), were examined histologically. The brains of three severely affected animals were stained for Nissl substance and those of eight (three severely affected) to reveal SDH.

\section{$N G F$ deprivation and evaluation}

NGF-deprived animals were produced as described by Johnson and his coworkers (1983). Young female guinea pigs were immunized with 200 $\mu \mathrm{g}$ of $2.5 \mathrm{~S}$ mouse NGF and were boosted with $30 \mu \mathrm{g}$ at monthly intervals to maintain titers (see Fig. 2). The titer of antibodies cross-reacting with purified guinea pig NGF (Rubin and Bradshaw, 1981) was determined using a modification of the chick dorsal root ganglion assay (Fenton, 1970; Levi-Montalcini et al., 1954). The few dams that developed titers to guinea pig NGF greater than 500 were mated. As shown in Figure 2 , offspring were classified operationally as described before (Johnson et al., 1980, 1983). Severely affected animals have higher titers against guinea pig NGF, do not respond to gentle noxious stimulation, and die shortly after birth. There is a correlated loss of over $80 \%$ of dorsal root ganglion cells. Moderately affected animals may have lower titers against guinea pig NGF, respond sluggishly to gentle noxious stimulation (when compared to normal animals), and survive the perinatal period. A $70 \%$ loss of dorsal root ganglion cells has been found in similar animals (see Johnson et al., 1983). Antibody titers were determined for some of the present animals and were in accord with previous findings (Johnson et al., 1983). In addition, sensitivities to tactile stimuli were assessed clinically by comparing the briskness, magnitude, and stereotypy of behavioral responses to gentle stimulation of the supraoptic and mystacial vibrissae in severely affected NGF-deprived animals and age-matched normal animals.

\section{Tissue preparation}

Our descriptions of the patterns of guinea pig central vibrissal repremarily on initial examination of brains stained to demonstrate cell
STEP I:

A. Immunize QGuinea Pigs (GP's)

B. GP makes $A b^{\prime}$ 's to $M N G F$.

C. Some Ab's crossreact with opNGF.

\section{STEP II:}
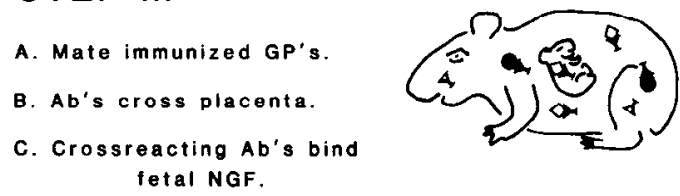

fetal NGF.

\section{STEP III:}

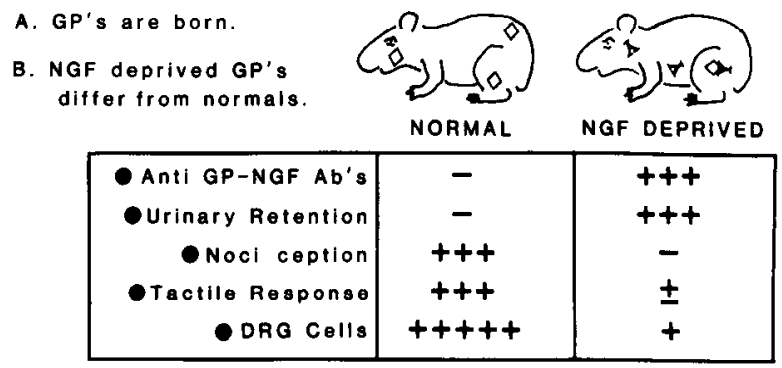

Figure 2. Schematic illustration showing how NGF-deprived guinea pigs are generated and their principal known characteristics. Step I, Mouse NGF is indicated by the filled symbols and guinea pig NGF by the open diamonds. The two molecules share antigenic determinants but are not identical. Step II, Antibodies that cross-react with guinea pig NGF are symbolized by the Ys. Step III, NGF-deprived guinea pigs are born and differ clinically and histologically from normal newborn guinea pigs. The procedure is very effective in selected individuals, but the number of dams that develop high titers to guinea pig NGF is small and the number of NGF-deprived offspring are few and survive for only 24-48 hr after birth.

bodies. Nitrocellulose-embedded brains were sectioned at $50 \mu \mathrm{m}$ and were stained with $0.12 \%$ thionin (e.g., Ma and Woolsey, 1984). All quantitative comparisons between normal and NGF-deprived animals were based on the analysis of SDH-stained materials. SDH histochemistry was performed by the Belford and Killackey (1979) modification of the method of Nachlas et al. (1957). Animals were anesthetized with an overdose of Nembutal and perfused transcardially with $10 \%$ glycerin in $0.5 \%$ formaldehyde. Brains were removed from the crania immediately, and blocked so that the brain stem could be cut transversely from the midcollicular level to the first cervical spinal segment, the thalamus cut horizontally, and the cortex cut in a plane tangential to the pia overlying the vibrissal representation in SmI (Zeigler, 1964). Immediately after blocking, brains were frozen in dry-ice-cooled heptane $\left(-70^{\circ} \mathrm{C}\right)$, and sectioned at $50 \mu \mathrm{m}$ in a cryostat at $-20^{\circ} \mathrm{C}$. Sections were stained with $0.55 \mathrm{~nm}$ nitro blue tetrazolium and $0.05 \mathrm{M}$ sodium succinate in $0.05 \mathrm{M}$ phosphate buffer, $\mathrm{pH} 7.2$, at $37^{\circ} \mathrm{C}$ until well colored.

Segments of the infraorbital nerves were cut distal to their entrance into the orbit through the infraorbital fissure and at a point $2.5 \mathrm{~mm}$ distal to the first transection (see Fig. 3). These ION segments, the facial skin, and the $\mathrm{V}$ ganglia were removed from the head and postfixed in $10 \%$ formol saline for several days. The vibrissal pads of the faces were stretched out flat, dehydrated and embedded in paraffin; $15 \mu \mathrm{m}$ serial sections were cut in a plane parallel to the skin surface (Durham and Woolsey, 1984). Every other section was stained with hematoxylin and eosin using standard protocols (e.g., Luna, 1968); the intervening sections were stained with silver using Ungewitter's protocol (1951) to demonstrate nerve fibers. The ION segments were embedded in paraffin, cut transversely at $10 \mu \mathrm{m}$, and stained with silver (Ungewitter, 1951). 


\begin{tabular}{lll}
\hline Table 1. List of specimens quantitated-animals (structures) \\
& $\begin{array}{l}\text { NGF- } \\
\text { deprived } \\
\text { animals }\end{array}$ \\
\hline B3 whisker & \\
$\quad$ Axons & $3(4)$ & $3(3)$ \\
Fascicles & $3(3)$ & $3(4)$ \\
F3 whisker & & \\
Axons & $3(4)$ & $3(3)$ \\
Fascicles & $3(3)$ & $3(4)$ \\
Infraorbital nerve & & $2(3)$ \\
Axons & $3(3)$ & $5(7)$ \\
Fascicles & $1(2)$ & $1(1)$ \\
Trigeminal ganglion & & $3(6)$ \\
$\quad$ Present study & $1(1)$ & $3(6)$ \\
$\quad$ Pearson et al. (1983) & $3(6)$ & $3(6)$ \\
N. interpolaris of V. & $4(8)$ & \\
Somatosensory cortex & $4(8)$ & \\
\hline
\end{tabular}

Trigeminal ganglia were embedded in paraffin, cut in $20 \mu \mathrm{m}$ sections parallel to the long axis of the ganglion (horizontal with respect to the crania), and stained with thionin.

\section{Quantitation}

Table 1 lists the specimens quantitated. Individual nerve fibers to the B-3 and F-3 follicles (whose locations on the face are shown in Fig. $1 b$ ) were counted at a magnification of $1146 \times$ in the first section in which the fibers entered the capsule of the follicle (see Figs. $3 h, 5$ ); this level was clear in all specimens. The number of fiber fascicles within the nerves, outlined by the perineuronal sheaths, was assessed in camera lucida drawings of each follicle made from the same section in which the fibers were counted. Individual fibers and fiber fascicles within each proximal ION segment were counted in a single section midway through the nerve segment at a magnification of $1146 \times$. Some sections from both severely affected NGF-deprived and normal animals were drawn using the camera lucida for fiber and fascicle counts (see Fig. 4). Cell counts in the trigeminal ganglia were made using standard methodologies, i.e., all neurons with nuclei containing visible nucleoli were counted in every 10th section (Konigsmark, 1970; Smolen et al., 1983).

In the brain-stem trigeminal nuclei, it is difficult to visualize the entire array of individual whisker representations in a single transverse section. The complete pattern of the vibrissal representation can be reconstructed by superimposing camera lucida drawings of all sections within each subnucleus on a drawing of a single section in which the pattern is relatively complete (see Fig. 6). The projected cross-sectional areas of such composite drawings will vary when the plane of sectioning is not truly transverse. The effects of such variation, which is common in cryostat-sectioned materials, on our quantitative comparisons of normal and NGF-deprived animals are minimal since (1) such deviations are equally likely in brains from normal and NGF-deprived animals, and (2) deviations in the angle of sectioning as great as $30^{\circ}$ only increase the apparent cross-sectional area by $12 \%$. Because of the curvature of the SmI cortex, it is not possible to visualize all of the individual whisker representations in a single tangential cortical section. A composite drawing of the complete pattern was made by aligning camera lucida drawings of three to four serial sections using representations of individual whiskers and blood vessels as guides.

All reconstructions of the central vibrissal representations were made without knowledge of whether the animal was normal or NGF-deprived. The cross-sectional areas of the reconstructed representations of the entire vibrissal pad and of each vibrissal row within it were measured using an electronic tablet (Summagraphics Bit Pad One RS232). All counts (except those of the $\mathrm{V}$ ganglia) and measurements in normal and NGF-deprived animals were performed in a random sequence by the same investigator and repeated at least $3 \times$ to insure consistency. Counts of the fibers and fiber fascicles at the B-3 and F-3 follicles were analyzed statistically using the Student $t$ test for comparing two independent groups with similar variances. Statistical analysis of measurements from $\mathrm{nVi}$ and the cortex employed the Behren's Fisher modification of the Student $t$ test for comparing two populations with different variances (Snedecor and Cochran, 1967).

\section{Results}

\section{Normal anatomy and nomenclature}

The vibrissal pads and brains of normal guinea pigs were examined to determine the arrangement of vibrissae on the face and the patterns and locations of the vibrissal representations in the CNS. The patterns in guinea pigs differ from those of mice and rats in that (1) there are six rather than five rows of vibrissae and of vibrissal representations, and (2) the rows are more irregularly aligned with respect to one another. The orientation of the representations within each station appear to be the same in mice, rats, and guinea pigs. Our observations are summarized in Figurc 1.

On the face (Fig. 1b), the caudorostral row of whiskers are designated $\mathrm{A}-\mathrm{F}$ in a dorsal to ventral progression. The rows are generally composed of four larger vibrissae, although row $B$ has only three and row $F$ has five. Within each row, individual vibrissae are numbered in the caudal to rostral direction. There are numerous small rhinal and labial sinus hairs.

Patterned representations homologous to the arrangement of the vibrissae on the face are in $n V p, n V i$, and $n V c$. As in other rodents, there is no pattern in $\mathrm{nVo}$. The vibrissal representation is most conspicuous and consistently discernible within $\mathrm{nVi}$; therefore, $\mathrm{nVi}$ was used for analysis in the brain stem (see Fig. 1c). Electrophysiological and lesion studies needed to definitively identify individual architectonic units as the representations of specific vibrissae have not been done in guinea pigs. Based on functional studies in other rodents, the architectonic units homologous to whiskers in the dorsal parts of the vibrissal pad (i.e., row A) are located ventrally and those homologous to the caudal whiskers located laterally. The pattern actually appears to be more regular in $\mathrm{nVi}$ than on the face because the lateral architectonic units all abut the trigeminal tract. Although the vibrissal representation in $\mathrm{nVi}$ extends approximately $1 \mathrm{~mm}$ in a rostrocaudal direction, we were unable to find a single transverse section in which the entire pattern is clearly discernible. Generally, the dorsal rows of the architectonic pattern are visible in the rostral portion of this subnucleus and the ventral rows are clearest in the more caudal parts.

There is a vibrissa-related architectonic pattern within the ventrobasal complex of the thalamus. However, because so many fiber bundles run through VB, it is exceedingly difficult to distinguish the pattern of individual architectonic units reliably. Accordingly, no further analysis of the thalamic vibrissal representation was made.

In guinea pigs, the cortical vibrissal representation in $\mathrm{SmI}$ is clearly visible as Friede (1960) first illustrated. In tangential sections, the architectonic representations homologous to the dorsal rows of whiskers are oriented posteriorly and those homologous to the caudal vibrissae within a row are oriented medially (consistent with the functional findings of Ziegler, 1964). Representations of the sinus hairs on the remainder of the face are contiguous with the representations of the rostral mystacial vibrissae. Unlike the pattern observed in $\mathrm{nVi}$, the pattern of the vibrissal representation in the cortex precisely reflects the irregularities in orientation of individual vibrissal rows on the face of an individual guinea pig.

\section{Functional deficits in NGF-deprived animals}

Sensory deficits observed in guinea pigs deprived of NGF prenatally have been described (Johnson ct al., 1983). The severcly affected animals we studied anatomically did not respond to 
NORMAL ANIMAL
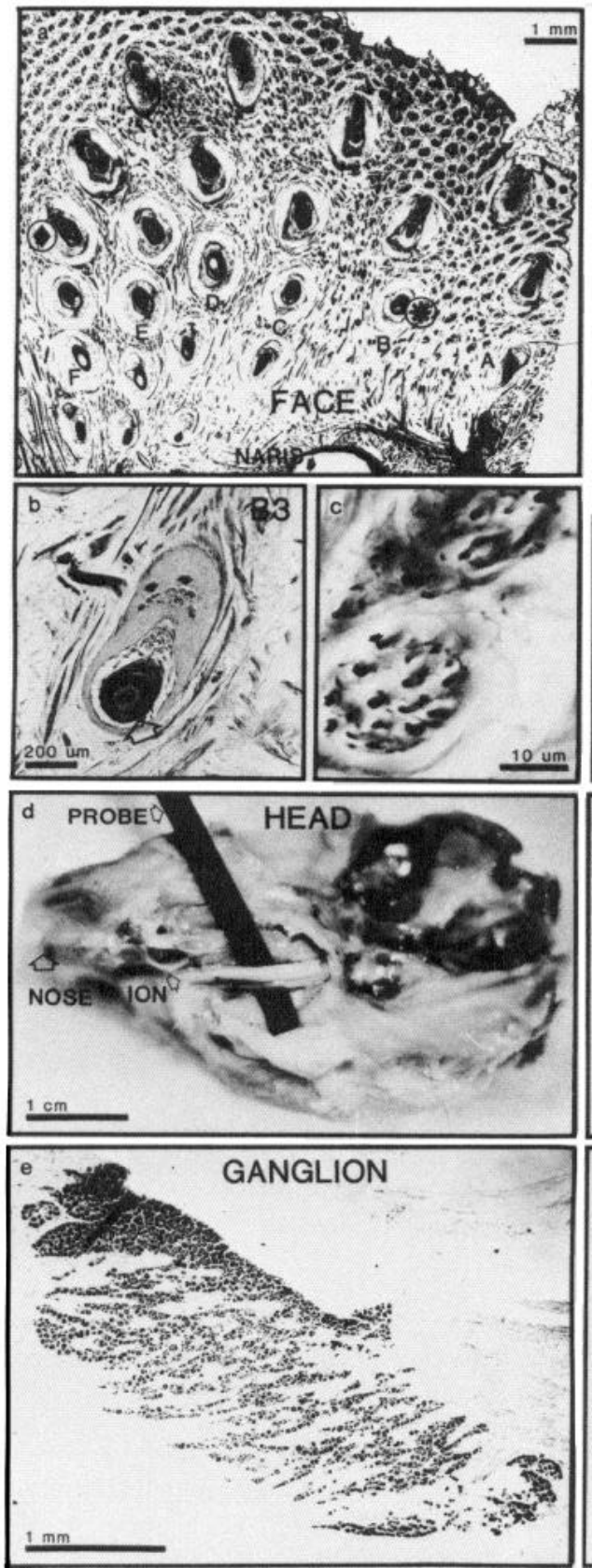

\section{NGF DEPRIVED ANIMAL}
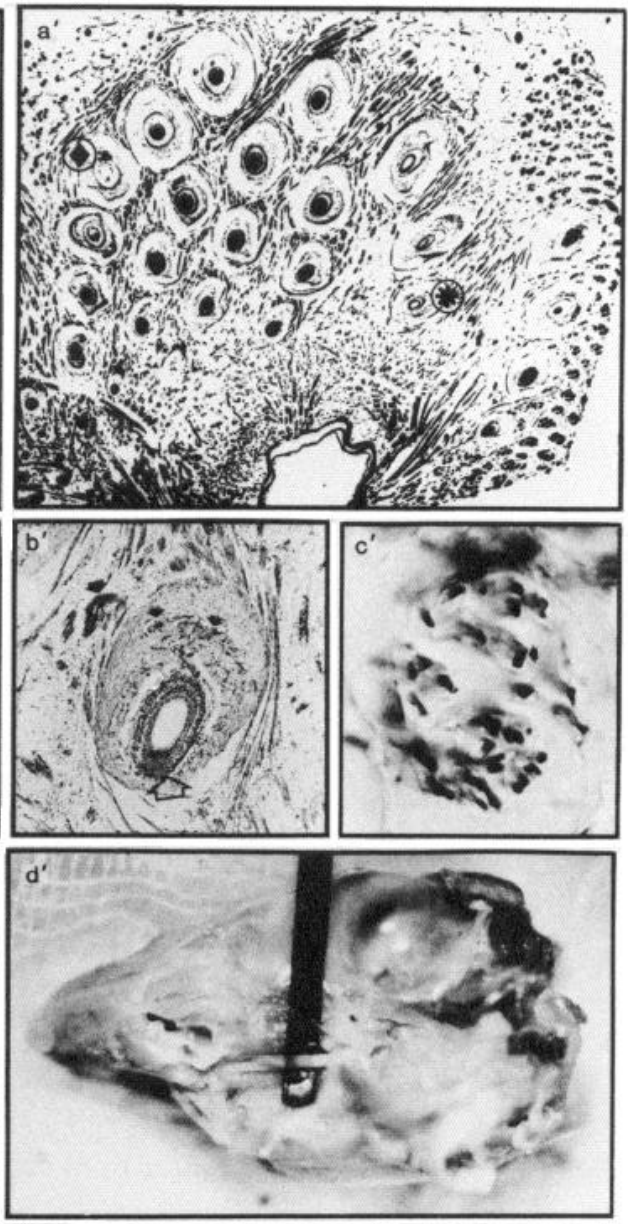

$e^{\prime}$

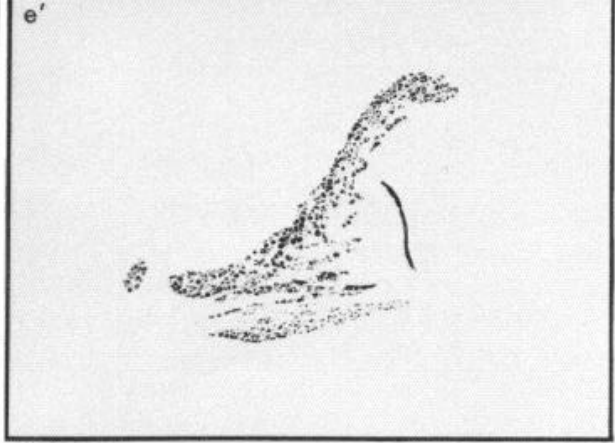

Figure 3. Photomicrographs and photographs of trigeminal system structures in the periphery of a normal animal (at left) and a NGF-deprived animal (at right) to demonstrate the alterations in peripheral innervation of NGF-deprived animals. In $a$ and $a^{\prime}, 15$ $\mu \mathrm{m}$ silver-stained sections through the face parallel to the surface of the skin demonstrate that there are no differences in the arrangement of the vibrissae on the face. The asterisks indicate follicles B-3, which are shown at greater magnifications in $b, b^{\prime}, c$, and $c^{\prime}$. The diamonds indicate follicles F-3. Caudal is up and ventral is to the left; the scale is indicated by the bar. In $b$ and $b^{\prime}$, the large solid arrows indicate the peripheral nerve bundles as they enter the B-3 vibrissal follicles; smaller arrows show individual fascicles within the follicles; open arrows indicate the hair shafts. Caudal is up and ventral is to the left; the scale is indicated by the bar. $c$ and $c^{\prime}$, Close-ups of nerve fascicles within the B-3 follicles. Orientation is as in $b$ and $b^{\prime}$; the scale is indicated by the bar. $d$ and $d^{\prime}$, Infraorbital nerve (ION), which innervates the vibrissal pad, in situ as it crosses the floor of the orbit. The ION of the NGF-deprived animal is visibly reduced in size from that of the normal animal. Dorsal is to the top, rostral to the left; the scale is indicated by the bar. $e$ and $e^{\prime}$, Longitudinal sections $(20 \mu \mathrm{m})$, oriented horizontally with respect to the crania, through the midpoint of each trigeminal ganglion. These are stained with thionin and demonstrate the severe cell loss observed in NGF-deprived animals. Medial is toward the top, rostral is to the left; the scale is indicated by the bar. noxious stimuli. We conclude that the nociceptive capacity of severely affected animals is functionally absent. Responses to manual stimulation of the vibrissae were much more variable. Initially, normal animals rapidly orient toward the side on which the mystacial vibrissae are stimulated. On repetitive stimulation, a normal animal will avoid the stimulus. In contrast, severely affected animals tend to become motionless after vibrissal stimulation, although, on rare occasions, they have been observed to orient toward or away from the stimulus. Stimulation of the supraorbital vibrissa normally elicits a mixture of orientation and avoidance responses; a blink has never been observed. Severely affected animals consistently respond to supraorbital vibrissal stimulation by blinking. Thus, it appears that NGF deprivation does not result in loss of the ability to respond to tactile stimulation within the region innervated by the ION even in the most severely affected animals. However, NGF deprivation is associated with deviations from behavioral responses observed in normal animals (see Fig. 2).

\section{Anatomical changes in NGF-deprived animals}

All components of the vibrissal system of normal and NGFdeprived animals were examined grossly and microscopically to verify and extend the previously reported changes in primary afferent innervation and to assess the impact of this decreased level of peripheral innervation on the central vibrissal representations. We found a marked decrease in the magnitude of peripheral innervation with changes in the organization of peripheral nerve fibers. However, neither the patterns nor the sizes 
NORMAL ANIMAL

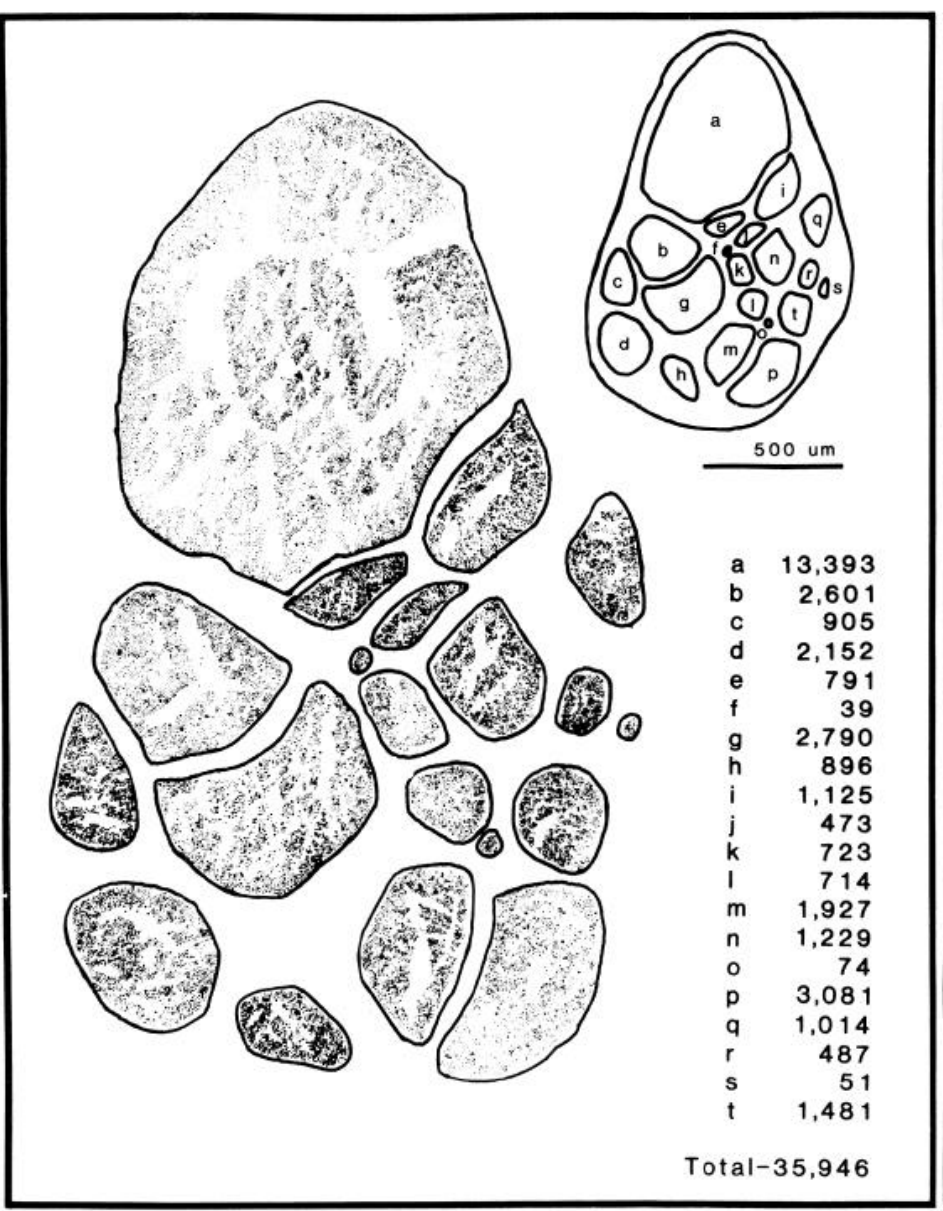

NGF DEPRIVED ANIMAL

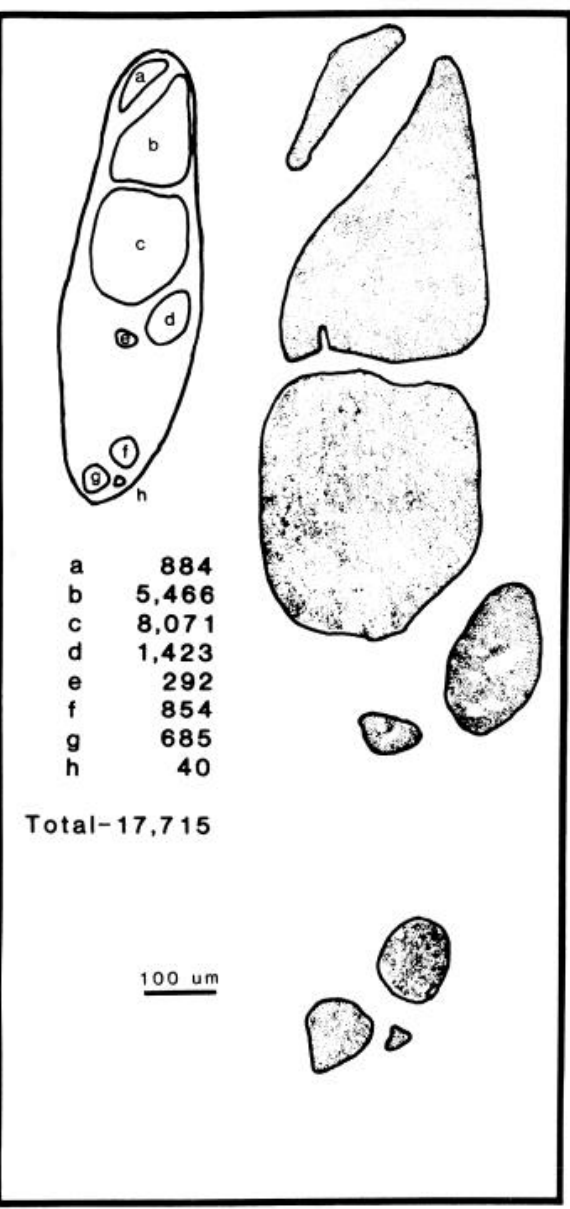

Figure 4. Camera lucida drawings showing silver-stained axons from the infraorbital nerves of a normal and a NGF-deprived guinea pig (Fig. 3, $c, e$, and $e^{\prime}$, shows photomicrographs of silver-stained axons such as those drawn here). As expected from Figure $3, d$ and $d^{\prime}$, the ION from the NGF-deprived animal has a much smaller cross-sectional area. There are fewer fascicles of fibers, as well as fewer fibers, in the specimens from the NGF-deprived animal, which are enumerated. Lower magnification scale applies to the drawings of the whole IONs; higher magnification scale applies to the drawings of the individual fascicles.

of the central vibrissal representations appeared to be altered. The volume of the trigeminal ganglia of guinea pigs severely affected by NGF deprivation was dramatically reduced, as shown in Figure $3, e, e^{\prime}$. In two such severely affected animals we found an $82 \%$ decrease in the number of $\mathrm{V}$ ganglion neurons $(18,000 \pm$ 2020 ) in NGF-deprived animals (compared to $92,000 \pm 16,100$ in two normal animals). The $82 \%$ reduction is identical to that reported by Pearson and his colleagues (1983), who examined six severely affected siblings of the severely affected animals we have studied. Animals judged by behavioral criteria to be moderately affected by NGF deprivation show a cell loss of $69 \%$ in $\mathrm{C} 8$ dorsal root ganglia, and we presume there is a similar loss in $\mathrm{V}$ ganglion neurons in moderately affected animals (Johnson et al., 1983).

The proximal portion of the ION is visibly reduced in diameter as compared to normal animals (Fig. 3, $d, d^{\prime}$ ). With the light microscope we are able to count $20,760 \pm 1880$ silverstained nerve fibers in the proximal part of the ION of severely affected animals as compared to $39,110 \pm 8120$ at an equivalent level of the purely sensory ION of normal animals (see Fig. 4). The level of fasciculation is significantly $(p \leq 0.005)$ reduced from an average of 20 fascicles in normal animals to 8 in the severely affected animals.

We were able to count an average of 82 and 88 fibers entering the B-3 and F-3 follicles (Figs. 3, $b, b^{\prime}$ and 5) of severely affected animals and an average of 165 and 165 entering the B-3 and F-3 follicles of normal animals. Again, there does not seem to be a preferential reduction of fibers of a single size class. The degree of fasciculation (Figs. 3, $c$ and $c^{\prime}$ and 5) is reduced from an average of 8 to 5 in B-3 and from an average of 5 to 3 in F3 . The reduction of nerve fibers to a dorsal follicle (B-3, -50\%) is comparable to that in a more ventral follicle ( $\mathrm{F}-3,-47 \%)$, suggesting that the extent of deafferentation is uniform over all parts of the vibrissal pad. These results clearly indicate that both the number of primary afferent neurons and their peripheral processes to the vibrissal pad are significantly decreased in guinea pigs deprived of NGF in utero.

In contrast to the substantial changes in the peripheral vibrissal innervation, the patterns of the whisker representations in the brain-stem trigeminal nuclei of severely affected animals are indistinguishable from those of normal animals as shown in Figure 6, $a-c$. The mean cross-sectional area of the transverse reconstructions of the $\mathrm{nVi}$ representations of severely affected animals is $0.72 \pm 0.15 \mathrm{~mm}^{2}$ as compared to $0.60 \pm 0.09 \mathrm{~mm}^{2}$ in normal animals. This increase in size is not statistically significant $(p \geq 0.05)$. As Table 2 shows, there are also no major differences in the relative sizes of the representation of individual rows of whiskers. Qualitative comparisons of the intensity 
NORMAL ANIMAL
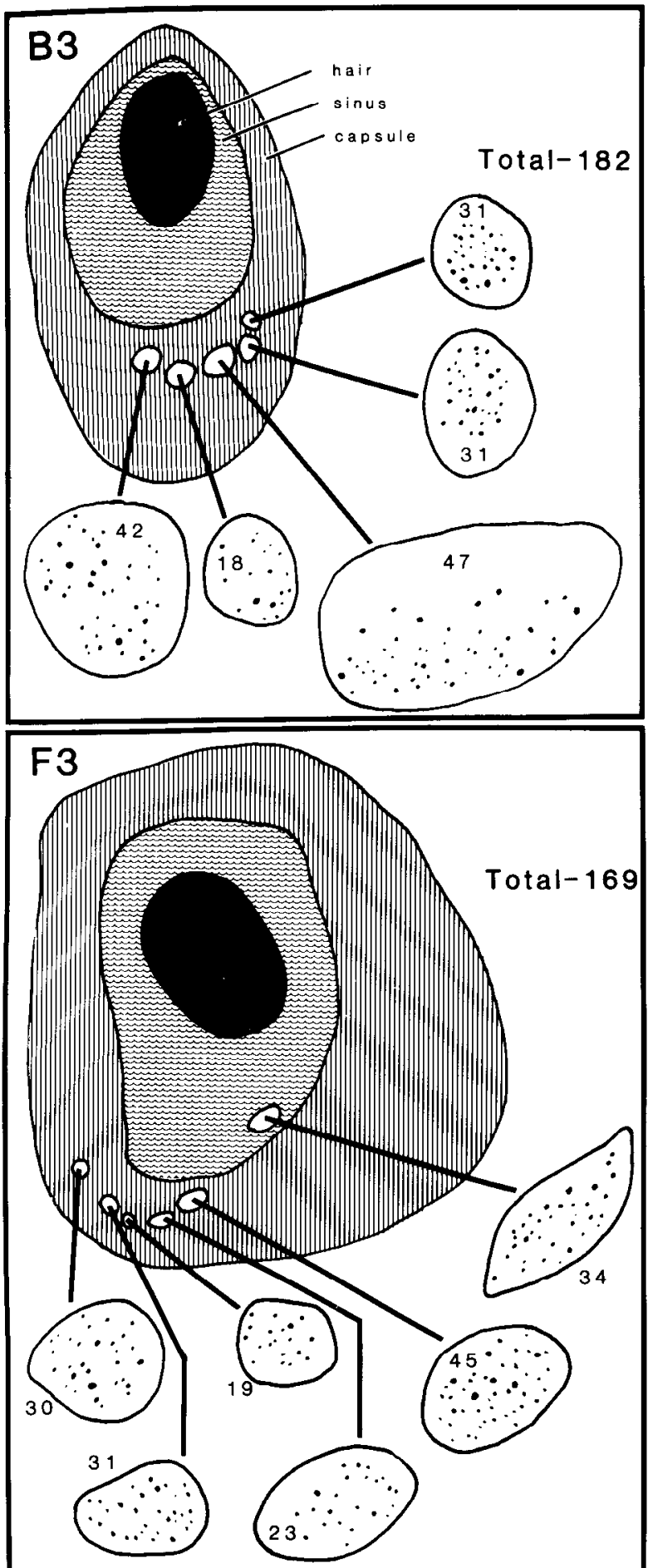

NGF DEPRIVED ANIMAL
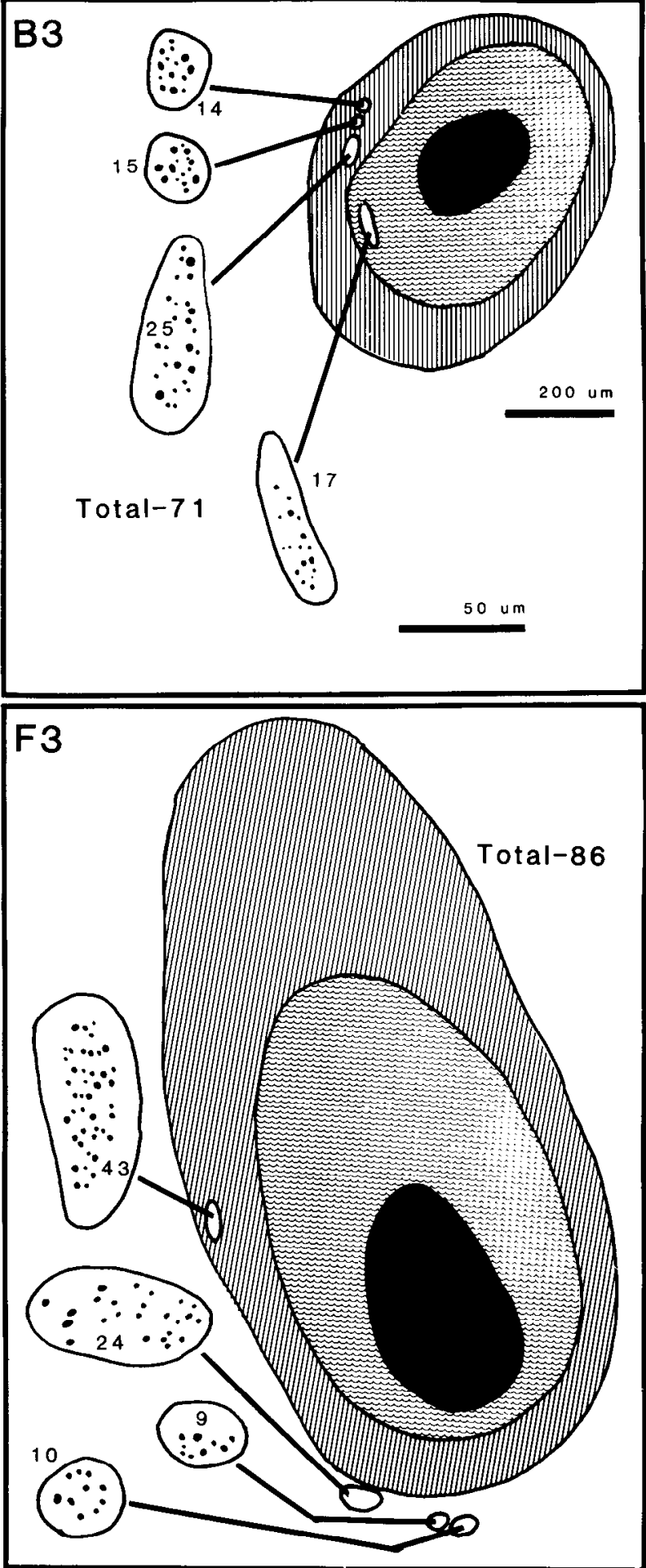

Figure 5. Semischematic camera lucida drawings of two silver-stained vibrissae each from a normal animal and a NGF-deprived animal. The histology of the follicles, cut parallel to the skin surface, has been simplified to show the whisker hair, the cavernous sinus, and the connective tissue capsules for each example (see also Fig. 3, $b$ and $b^{\prime}$ ). Each fascicle of nerves innervating each vibrissa is shown and the number of axons counted indicated. There are fewer nerve fibers at roughly equivalent levels of the follicles in the NGF-deprived guinea pig than in the normal animal. The $200 \mu \mathrm{m}$ bar gives the magnification of the whisker follicles, the $50 \mu \mathrm{m}$ bar the individual nerves.

of staining of trigeminal structures relative to that of other structures not known to be affected by NGF deprivation (e.g., the hypoglossal nucleus) do not indicate any significant differences in SDH staining between NGF-deprived and normal animals.
The patterns of the cortical vibrissal representations of severely affected animals are indistinguishable from those of normal animals (Fig. 6, $d, d^{\prime}$ and $e, e^{\prime}$ ). The mean cross-sectional area of the cortical representations in severely affected animals 
NORMAL ANIMAL
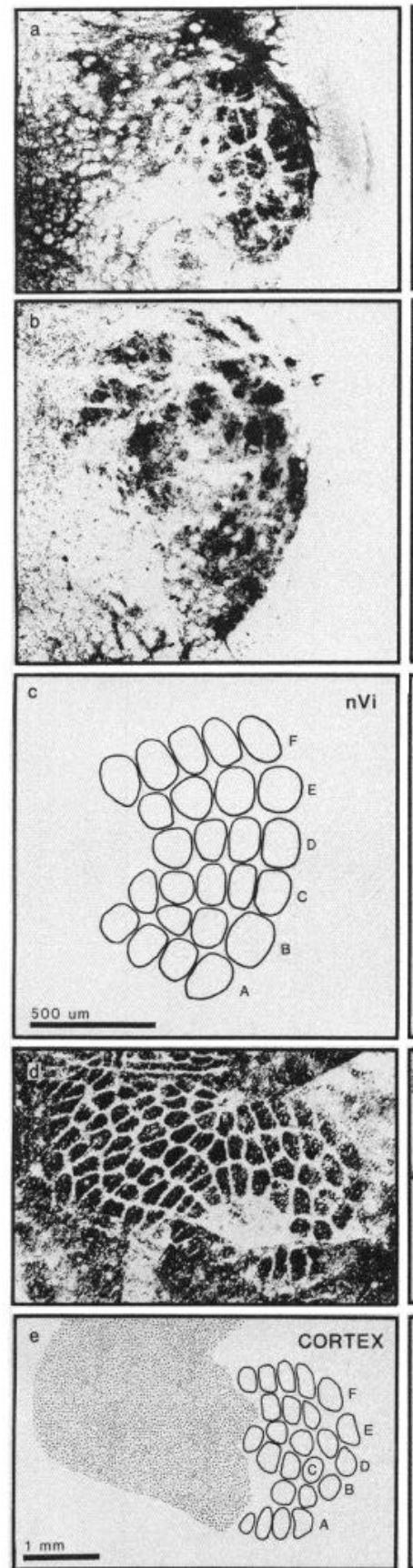

\section{NGF DEPRIVED ANIMAL}
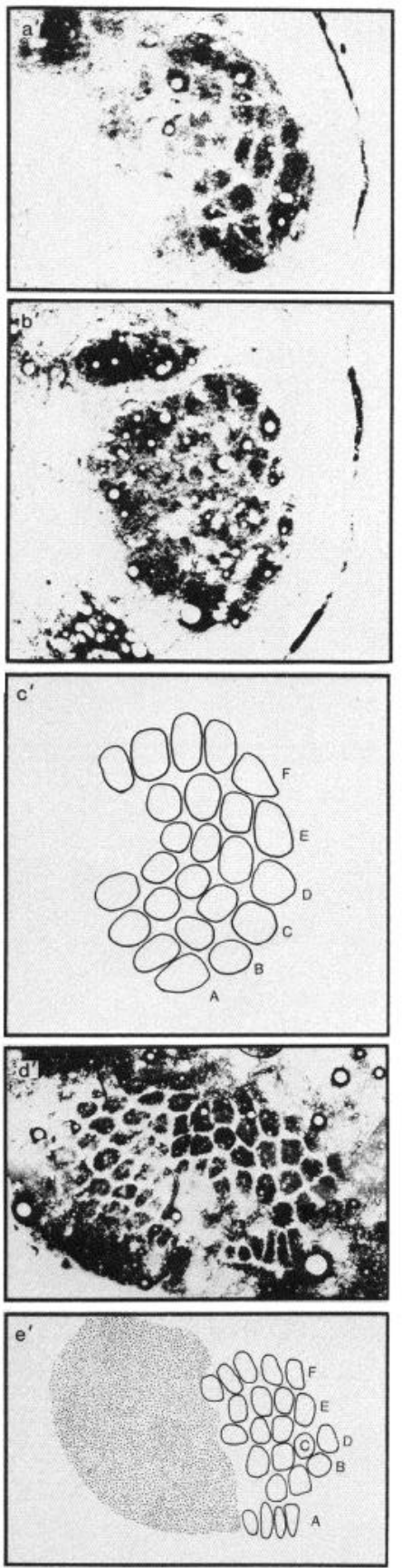

Figure 6. Photomicrographs and line drawings of the vibrissal representations in $\mathrm{nVi}$ and the cortex of a normal animal (left) and a severely affected NGF-deprived animal (right). $a, a^{\prime}, b$, and $b^{\prime}$, Representative photomicrographs of $50 \mu \mathrm{m} \mathrm{SDH}$-stained transverse sections through equivalent levels of the right $\mathrm{nVi}, c$ and $c^{\prime}$, Transverse reconstructions of the $\mathrm{nVi}$ representation in both animals. The patterns and apparent sizes of the representations are very similar. In $a, a^{\prime}, b, b^{\prime}, c$ and $c^{\prime}$, dorsal is toward the top and medial to the left; the scale is indicated by the bar in panel $c$. $d$ and $d^{\prime}$ show photomontages of the left cortical barrel fields of the animals depicted; $e$ and $e^{\prime}$ show the reconstructions corresponding to them. The patterns and apparent sizes of the vibrissal representations in SmI are also very similar. In $d, d^{\prime}, e$, and $e^{\prime}$, anterior is up and lateral toward the left; the scale is shown by the bar in $e$.
Table 2. Absolute ${ }^{a}$ and relative ${ }^{b}$ sizes of whisker row representations in normal and NGF-deprived guinea pigs

\begin{tabular}{|c|c|c|c|c|}
\hline \multirow[b]{2}{*}{$\begin{array}{l}\text { Whisker } \\
\text { row }\end{array}$} & \multicolumn{2}{|c|}{$\mathrm{N}$. interpolaris of $\mathrm{V}$. } & \multicolumn{2}{|c|}{ Somatosensory cortex } \\
\hline & $\begin{array}{l}\text { Normal } \\
\text { animals }\end{array}$ & $\begin{array}{l}\text { NGF- } \\
\text { deprived } \\
\text { animals }\end{array}$ & $\begin{array}{l}\text { Normal } \\
\text { animals }\end{array}$ & $\begin{array}{l}\text { NGF- } \\
\text { deprived } \\
\text { animals }\end{array}$ \\
\hline A & $\begin{array}{r}9.9 \\
(18)\end{array}$ & $\begin{array}{l}12.9 \\
(19)\end{array}$ & $\begin{array}{l}27 \\
(13)\end{array}$ & $\begin{array}{l}30 \\
(15)\end{array}$ \\
\hline B & $\begin{array}{r}6.7 \\
(12)\end{array}$ & $\begin{array}{r}7.4 \\
(11)\end{array}$ & $\begin{array}{l}27 \\
(13)\end{array}$ & $\begin{array}{l}28 \\
(14)\end{array}$ \\
\hline $\mathrm{C}$ & $\begin{array}{r}9.0 \\
(16)\end{array}$ & $\begin{array}{l}11.8 \\
(18)\end{array}$ & $\begin{array}{l}31 \\
(15)\end{array}$ & $\begin{array}{l}34 \\
(17)\end{array}$ \\
\hline $\mathrm{D}$ & $\begin{array}{r}9.3 \\
(17)\end{array}$ & $\begin{array}{l}10.9 \\
(16)\end{array}$ & $\begin{array}{l}33 \\
(16)\end{array}$ & $\begin{array}{l}32 \\
(16)\end{array}$ \\
\hline $\mathrm{E}$ & $\begin{array}{r}9.5 \\
(17)\end{array}$ & $\begin{array}{l}11.4 \\
(17)\end{array}$ & $\begin{array}{l}40 \\
(20)\end{array}$ & $\begin{array}{l}41 \\
(20)\end{array}$ \\
\hline $\mathrm{F}$ & $\begin{array}{l}11.5 \\
(21)\end{array}$ & $\begin{array}{l}13.0 \\
(19)\end{array}$ & $\begin{array}{l}45 \\
(22)\end{array}$ & $\begin{array}{l}39 \\
(19)\end{array}$ \\
\hline
\end{tabular}

\footnotetext{
${ }^{a}$ Averages from all specimens measured in $\mathrm{mm}^{2}\left(\times 10^{-2}\right)$.

${ }^{b}$ Expressed as a percentage of the total of all rows in parentheses.
}

$\left(2.59 \pm 0.12 \mathrm{~mm}^{2}\right)$ is virtually identical to that in normal animals $\left(2.56 \pm 0.25 \mathrm{~mm}^{2}\right)$. As in $\mathrm{nVi}$, there are no major differences in the relative sizes of the cortical representations of particular whisker rows (Table 2).

The quantitation of the trigeminal pathway in normal and NGF-deprived guinea pigs is summarized graphically in Figure 7. The differences between NGF-deprived and normal animals are greatest in the $\mathrm{V}$ ganglia, significant but less than expected in the sensory periphery, and nil in the central vibrissal representations.

\section{Discussion}

This study of the effects of in utero NGF deprivation on the guinea pig somatosensory system is related to three heretofore seemingly different topics. First, the study is the first careful characterization of a major sensory pathway in animals subjected to early NGF deprivation. Second, the results extend experiments on mismatching, by underloading the sensory periphery, to the developing mammalian CNS. And third, the results are of interest for studies of the rodent trigeminal pathway in particular.

The observation that NGF deprivation of fetal guinea pigs could result in the loss of up to $85 \%$ of V ganglion cells (Pearson et al., 1983) immediately raised the possibility that the pattern and size of the central vibrissal representations would also be altered. We felt that an $85 \%$ deficit of the primary afferent neurons might lead to major changes in the central vibrissal representations. First, the central whisker representations would be abnormally patterned if more than $18 \%$ of the normal level of ganglion cells were required to form and/or maintain central patterns. Second, the size of the vibrissal representations would be reduced if the amount of central territory allocated were directly proportional to the magnitude of peripheral innervation. In the periphery, we found a smaller decrease in the number of fibers innervating the vibrissal follicles (50\%) than in the number of $\mathrm{V}$ ganglion cells (85\%). Centrally, the vibrissal representations in the brain stem and cortex were indistinguishable in both pattern and size from those of normal animals. These findings indicate that $18 \%$ of the normal complement of $\mathrm{V}$ ganglion neurons can establish normally patterned and sized central vibrissal representations. However, before discussing these re- 


\section{Locus}

(Normal Value \pm S.D.)

Number of Axons to B3 Whisker

(165 \pm 50$)$

Number of Axons

to F3 Whisker

(164 \pm 16$)$

Number of Axons

in Infraorbital Nerve

$(39,110 \pm 8,122)$

Number of Neurons in Trigeminal Ganglion ${ }^{1}$

$(51,000 \pm 7,700)$

Whisker Area

in $\mathbf{N}$. Interpolaris of $\mathbf{V}$

$\left(0.80 \pm 0.09 \mathrm{~mm}^{2}\right)$

Whisker Area

in Somatosensory Cortex

$\left(2.57 \div 0.25 \mathrm{~mm}^{2}\right)$

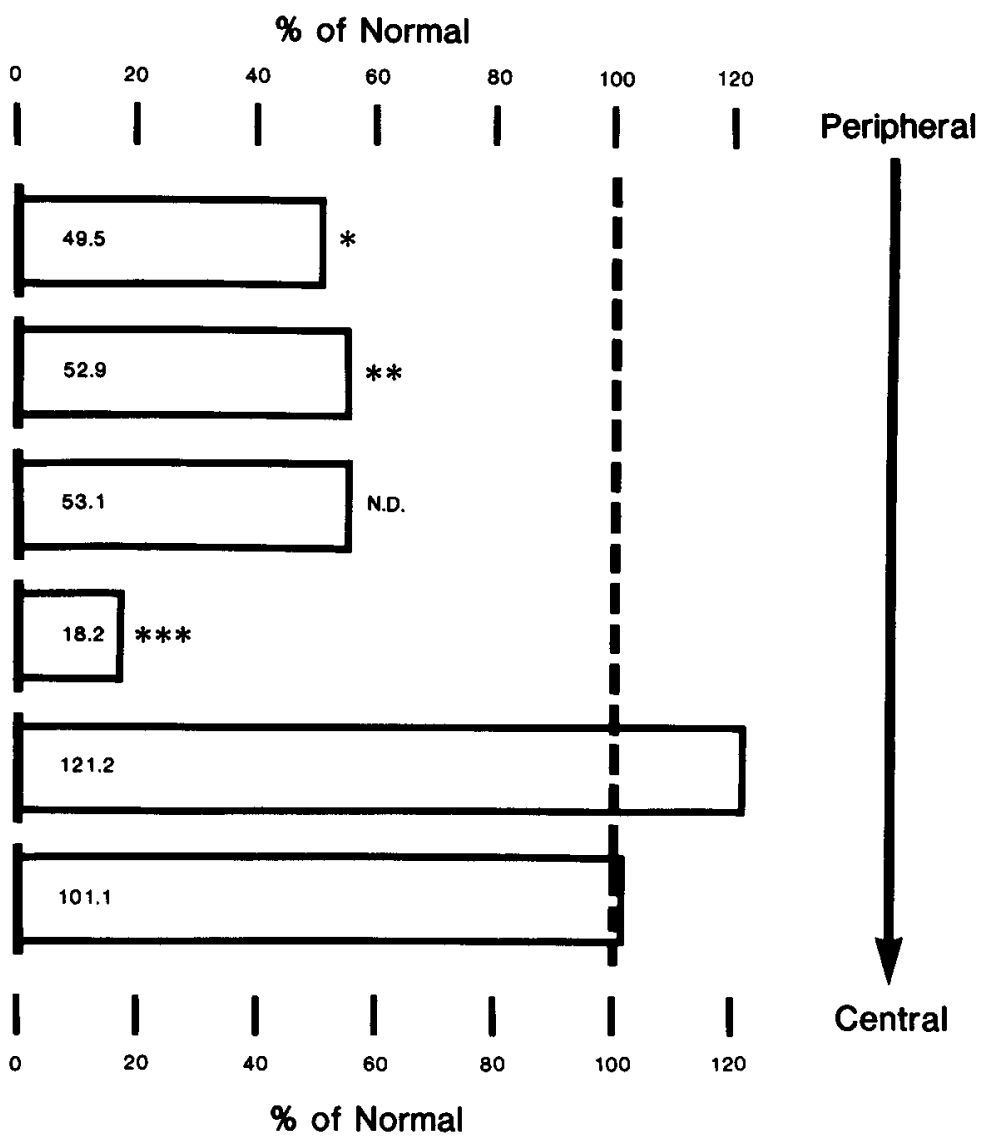

Figure 7. Graph of the sizes of vibrissae-related structures in severely affected NGF-deprived animals as a percentage of those in normal animals. The mean value of each locus from normal animals is given in parentheses beside the appropriate locus. Asterisks indicates statistical significance as follows: ${ }^{*} p \leq 0.0500,{ }^{* *} p \leq 0.0250$ level, and ${ }^{* * *} p \leq 0.0005$ (Student's $t$ test); N.D. indicates that the sample size was too small for meaningful analysis. Although the level of peripheral innervation is significantly decreased, the size of the central vibrissal representations is unchanged.

sults, it is essential to consider whether the $\mathrm{V}$ ganglion cell loss resulting from NGF deprivation in utero occurs before or during the time periods in which previous studies have demonstrated anatomical plasticity of the central vibrissal representations. We do this by reviewing the time courses of antibody transfer in guinea pigs and of the NGF dependence of sensory neurons, and by reviewing the development of the guinea pig and the guinea pig brain as described in the literature.

\section{Cell death occurs while the system is plastic}

Studies of immunity in guinea pigs indicate that there is significant transplacental transfer of maternal antibodies. Maternal antibodies begin to cross the placenta and enter the fetal circulation by the 30th day of gestation (E30). Between E30 and E50 the levels of antibodies in fetal blood rise rapidly, to become $2.5 \times$ that of the mother (reviewed by Brambell, 1970). The transplacental antibody transfer continues after E50, but there is some disagreement as to whether antibody levels fall slightly (Barnes, 1959), remain stable (Leissring and Anderson, 1961), or continue to increase (Al-Nadji, 1965). In our animals, the titer of anti-NGF in newborn sera is $50-100 \%$ that of maternal sera (Johnson et al., 1983).

The relationship between sensory neurons and NGF has been examined using two experimental parameters: (1) sensitivity, which assesses the pharmacological effect of exogenous NGF on neurite extension, and (2) dependence, which monitors the neuron's physiological requirement for NGF in order to survive. Classical studies on chick embryos (reviewed by Greene, 1977) have found that the periods of NGF action determined using these two methods are very similar, but that a smaller less diverse population of neurons appears to be sensitive to exogenous NGF. In mice, in vitro NGF sensitivity of $\mathrm{V}$ ganglion neurons begins on $\mathrm{E} 11$ and continues at least through birth at E21 (Davies and Lumsden, 1984). Embryonic sensory neurons in mice and rats have also been shown to be dependent on NGF for survival in vitro (Varon et al., 1973) and in vivo (Gorin and Johnson, 1979), but the time course of NGF dependence has not been characterized as well. At least $85 \%$ (perhaps all) of neural-crest-derived sensory neurons depend on NGF from peripheral targets for a limited period in development, one commencing shortly after the period of initial ncuritc cxtension in vivo (at E22 in guinea pigs) and continuing beyond the period of naturally occurring cell death. The results of autoimmune NGF deprivation (Johnson et al., 1980, 1983), which are consistent with tissue culture studies in other species, demonstrate that guinea pig neural-crest-derived sensory neurons are physiologically dependent on NGF for survival during fetal life. Since $85 \%$ of neural-crest-derived sensory neurons die if exposed to maternal anti-NGF antibodies during fetal life, the period of NGF dependence in guinea pigs must overlap the period of transplacental antibody transfer (E30-E68).

The maturity of guinea pigs at birth might suggest that only parturition is delayed with respect to that in mice. However, comparison of various gestational events indicates that the initial development of the guinea pig is delayed. For the vibrissal system, events occurring early in gestation appear to be delayed by about $9 \mathrm{~d}$. Trigeminal ganglion neurons appear from E16 to E17 in guinea pigs (Scott, 1953) and from E9 to E10 in mice (Davies and Lumsden, 1984; Rugh, 1968). Neurite extension from the $\mathrm{V}$ ganglion toward the maxillary process is first ob- 
served on E22 in guinea pigs (Scott, 1953) and E12 in mice (Davies and Lumsden, 1984). Vibrissal follicle formation begins on E23 in guinea pigs (Scott, 1953) and E1 1 in mice (Dun, 1959; Yamakado and Yohro, 1979). The delays are longer later in fetal life. The cortex begins to assume its adult layered form on E41 in guinea pigs (Peters and Flexner, 1950) and on PND 6 or the 25 th postconception day (PCD 25) in mice (Rice, 1975). The barrel field in the cortex forms over E39-E41 in guinea pigs (Rice, 1983) and PND 6-PND 7 (PCD 25-PCD 26) in mice (Rice and Van der Loos, 1977). These comparisons indicate a 14-20 d delay in the initial formation, maturation, and plasticity of connections within the vibrissal system of guinea pigs as compared to mice.

In rats and mice, there is a close correlation between the maturation of architectonic patterns in the central vibrissal representations and anatomical refractoriness to alterations produced by manipulation of the periphery (e.g., Belford and Killackey, 1980; Weller and Johnson, 1975). In mice, the "critical" periods during which surgical deafferentation of the whiskers results in architectonic alterations of the central vibrissal representations appear to end on PND 5 (PCD 24) in the cortex (Jeanmonod et al., 1981; Weller and Johnson, 1975; Woolsey and Wann, 1976) and before PND 3 (PCD 22) in the thalamus (Durham and Woolsey, 1984; Woolsey et al., 1979). In the mouse brain stem, the pattern but not the size of the vibrissal representations may be altered as a result of surgical denervation occurring as late as PND 10 (PCD 29); however, these observations are complicated by degeneration of the primary afferent fibers (Durham and Woolsey, 1984; and Ma, unpublished observations). This information suggests that the $85 \% \mathrm{~V}$ ganglion cell loss resulting from autoimmune NGF deprivation of fetal guinea pigs occurs well before the ends of the "critical periods" for establishing patterns in all of the central $\mathrm{V}$ stations.

\section{Peripheral changes}

The peripheral innervation density for tactile organs at the vibrissal pad can be determined by counting the nerve fibers that enter specific follicles. A particular whisker is easily identifiable in all animals of the same species. We found no apparent differences in the structure of individual whisker follicles or in their arrangement on the face between normal and NGF-deprived animals. The highly comparable decreases in the number of fibers supplying the earlier-developing B-3 follicle $(47.5 \%)$ and the later-developing F-3 follicle (51.1\%) show that the vibrissal pad is uniformly deafferentated. Our observation that the terminal innervation of the vibrissal follicles is not reduced to as great an extent as the $\mathrm{V}$ ganglion cells indicates that surviving sensory neurons can partially offset the loss of other primary sensory afferents.

The difference in the reductions of peripheral axons and of the number of $\mathrm{V}$ ganglion cells could be explained by (1) persistence of axon collaterals that are normally retracted and/or (2) active axonal sprouting in response to uninnervated target tissue. Transient axon collaterals, which often arise near the neuronal soma, are prevalent within the developing central (Clarke and Cowan, 1975; O'Leary and Cowan, 1982; O'Leary et al., 1981; Rakic, 1977; Stanfield et al., 1982) and peripheral nervous systems (Bennett and Pettigrew, 1974; Brown et al., 1976; Lichtman, 1977; Lichtman and Purves, 1980; Redfern, 1970). However, this developmental phenomenon has not been clearly demonstrated within the somatosensory periphery (e.g., Smith, 1983), despite Speidel's $(1941,1942)$ classical observations suggesting it. Sprouting of novel axon collaterals from the distal parts of intact axons in response to vacated targets has been described both centrally (Azmitia et al., 1978; Hulsebosch et al., 1984; Liu and Chambers, 1958; Stanfield and Cowan, 1979; Steward et al., 1976) and peripherally (Brown and Ironton,
1978; Courtney and Roper, 1976; Edds, 1953; Hoffman, 1952; Murray and Thompson, 1957). There is considerable precedence for this phenomenon within the somatosensory systcm (e.g., Devor et al., 1979; Diamond, 1982; Jackson and Diamond, 1984; Wall et al., 1982; Weddell et al., 1941).

One way to distinguish between the persistence of transient collaterals and the sprouting of novel collaterals is to examine the morphology of the primary afferent fibers in normal and NGF-deprived animals. Greater-than-normal branching near the soma would suggest that transient collaterals had been maintained, while more branching near the vibrissae would indicate the sprouting of novel processes. We counted axons in the whole ION, and it is possible that there could be a differential loss of vibrissal and nonvibrissal components of the ION with NGF deprivation. Given the generalized action of NGF at least for all neural crest derivatives (e.g., Pearson et al., 1983), this would seem to be very unlikely. Furthermore, in other rodents it is known that $80-90 \%$ of ION-related Gasserian neurons innervate the vibrissae (Savy et al., 1981). Even if the figures were smaller in the guinea pig, which is unlikely from the central projections (Fig. 5) and known cortical function (Zeigler, 1964), the changes observed in ION fiber counts still are largely, if not exclusively, related to axons to the whiskers. The findings of nearly identical decreases in the number of fibers within the proximal ION and its branches to individual vibrissal follicles support the hypothesis that some axon collaterals to the whiskers, which would normally be retracted, persist.

We counted the number of fiber fascicles within the proximal and distal parts of the ION to determine whether the intrinsic organization of the ION of NGF-deprived animals differed from that of normal animals. It has been suggested that fasciculation within the ION is important in guiding the primary afferent fibers to their appropriate targets (Erzurumlu and Killackey, 1983). However, our results, showing a decrease in the number of fascicles and normal patterning of the vibrissal representation in $\mathrm{nVi}$, indicate that a given pattern of fasciculation is not necessary for normal central pattern formation.

In rats, the majority of $\mathrm{V}$ ganglion cells stimulated by whisker movement respond to the deflection of only one vibrissa (Zucker and Welker, 1969). It seems likely that the relative increase in peripheral fibers innervating the vibrissae following the loss of $V$ ganglion neurons would obscure but not eliminate this usual precise pattern. The results of our behavioral tests for tactile sensibility are consistent with such a reduction in the precision of peripheral innervation. That the vibrissal pad is uniformly deafferentated, argues against distortion of specific vibrissal innervation as a consequence of shifts in the levels of innervation of individual vibrissae relative to one another.

The relative increase in peripheral fibers innervating the vibrissae raises the possibility that the central axons of the $\mathrm{V}$ ganglion neurons may be relativcly more numcrous in NGFdeprived animals. However, the anatomy of the brain-stem $\mathrm{V}$ complex makes it difficult to assess central $\mathrm{V}$ projections quantitatively. (We did not count the fibers in the trigeminal root, but studies addressing this issue are presently under way.) In the past, the roles of peripheral nerve fibers, primary afferent neurons, and their central projections in establishing the pattern and size of central somatotopic representations have not been clearly distinguished (for further discussion, see Jeanmonod et al., 1981).

\section{Central changes}

The patterns of the vibrissal representations in the brain stem and cortex were examined in order to partially characterize the relationship between the number of primary afferents and the central architectonic patterns. Previous studies have raised the possibility that the peripheral innervation may be important 
only in the initial formation of central architectonic patterns, since surgical disruption of the whisker nerves after the mature architectonic patterns become discernible does not produce anatomical changes in the thalamic or the cortical vibrissal representations (Belford and Killackey, 1980; Durham and Woolsey, 1984; Killackey et al., 1976; Rice and Van der Loos, 1977; Weller and Johnson, 1975; Woolsey and Wann, 1976; Woolsey et al., 1981). Because primary afferents begin to enter the spinal trigeminal nucleus early in development -E22 in the guinea pig (Scott, 1953) and E13 in the rat (Erzurumlu and Killackey, 1983)-well before they are destroyed by either NGF deprivation or surgery, the architectonic patterns observed may well reflect two distinct phenomena: (1) initial specification of a pattern and (2) its subsequent stabilization. There are no differences in the pattern of the vibrissal representations of normal and severely affected NGF-deprived animals, clearly demonstrating that $18 \%$ of the normal number of $\mathrm{V}$ ganglion cells and/or $50 \%$ of the normal number of peripheral axons is sufficient to establish the normal central architectonic patterns. There are two interpretations of this result. First, active central pattern formation may require fewer than $50 \%$ the normal number of primary afferents and/or $18 \%$ of the normal number of ganglion cells. Second, and most probable, central pattern stabilization may depend on the initial pattern of peripheral innervation rather than its magnitude. It is likely that cell death resulting from NGF deprivation occurs after pattern specification but before pattern stabilization has taken place.

The quantification of the central vibrissal representations of normal and NGF-deprived animals was done to determine if the amount of central territory allocated to a peripheral structure was directly proportional to the magnitude of the peripheral innervation. As we observed no significant differences in the size of the vibrissal representations in either $\mathrm{nVi}$ or in $\mathrm{SmI}$ cortex, the territory in a central nucleus or cortical field available to a given sensory representation, but not the pattern of that representation, would seem to be entirely independent of the periphery. This conclusion is consistent with previous work in mice and rats in which subsets of vibrissae were deafferentated during critical periods. The quantitative data from such experiments show that the extent of the total target regions is the same in partially deafferentated and normal animals even though the proportions of the target regions occupied by the representations of the damaged and uninjured vibrissae subsets had changed (e.g., Woolsey and Wann, 1976; Woolsey et al., 1979; for a fuller discussion, see Woolsey, 1978, pp. 359-360).

It would not be appropriate here to review the cxtensive and complex literature on projection source-target interactions that has been developed using the retinotectal system of principally lower vertebrates. However, the present study and that of Ito and Seo (1983), in which part of the SmI is removed, have similarities to "mismatch" experiments in which either the eye is partially extirpated-peripheral underloading-or the tectum was partially removed - target compression. In many species, both peripheral underloading and target compression experiments performed at the appropriate developmental time result in correct mapping of the retina on its target. In the latter, the entire map is compressed; in the former, the projections of the retina expand to fill the normal tectum. Ito and Seo's compression experiments show that the full map of the vibrissae will fill a smaller cortical target and that the relative size of the individual elements (whisker patches) is scaled down proportionately. Results from our work, a kind of peripheral underloading, demonstrate that relatively few sensory neurons will fill a central target and map to it appropriately. Together these results suggest that mammalian nervous systems obey the same rules that have been defined in "lower forms." One advantage of the rodent trigeminal system is that it is relatively straight- forward to assess the projection patterns after a variety of manipulations. It is considerably more difficult to assess the projection patterns in the retinotectal system, the elegant experiments of Fujisawa (1982) and those of Thanos and Bonhoeffer (1983) notwithstanding.

The present data clearly indicate that a substantial, early, uniform partial deafferentation does not alter either the size or the distribution of central projections related to the whiskers. Earlier work from our laboratories (Durham and Woolsey, 1984; Woolsey and Wann, 1976; Woolsey et al., 1981) and others (Jeanmonod et al., 1981; Waite and Cragg, 1982; Weller and Johnson, 1975) has shown that surgical manipulation of the periphery can prevent the proper formation of whisker-related patterns when the infraorbital nerve is cut or altered when the afferents to different groups of whiskers are interrupted. NGF deprivation destroys the peripheral neurons much earlier than postnatal surgery would. Surgical lesions appear to disconnect the system from information necessary for central projections to form appropriate patterns. The mechanisms by which this information is passed to, say, the thalamocortical projection are under active investigation but remain unknown. From experiments in which selected groups of vibrissae are deinnervated, it seems clear that intact parts of the system have a competitive advantage during critical periods in development by which they can effectively enlarge their projection territories at the expense of these disconnected and presumably less competitive neighbors (Guillery, 1972; Purves and Lichtman, 1980). What the results from NGF-deprived guinea pigs indicate is that so long as the CNS is connected to the periphery and so long as the relative strengths of inputs from the periphery are maintained, then the appropriate segregation of central fibers will take place. In a word, the competitive balance between groups of fibers related to specific whiskers is still intact, resulting in normal looking, but possibly functionally altered, central projections. It is difficult to imagine how this important point could have been established experimentally without the guinea pig autoimmune model.

By several functional methods it is known that after lesions to selected groups of whiskers, the remaining whiskers project to the appropriate, if expanded, cortical territories. In this regard, the altered projections appear to be functionally normal. A number of workers have shown that these projections can be functionally abnormal (see Simons et al., 1984, for details). As discussed at some length before, this observation is most economically explained by a peripheral mechanism. Our present obscrvations on the patterns of peripheral innervation in the NGF-deprived guinea pigs indicate that a reduced number of trigeminal ganglion neurons can support a greater number of axonal branches than usual in the ION and in the sensory periphery. When this increased innervation develops in the guinea pig is not known, but it is conceivable that a peripheral balancc is disturbed in both NGF deprivation and with lesions to groups of whiskers. In the deprived guinea pigs, this leads to altered behavior, which is consistent with an inability to accurately localize a peripheral stimulus; in animals with selective whisker damage, it could explain abnormalities in cortical receptive fields. The findings of both kinds of experiments are consistent with another kind of competition, which is part of the normal developmental process, namely, the competition of peripheral axons for peripheral territories (e.g., Diamond, 1982). That both peripheral and central competition are important factors in the normal development of the mammalian somatosensory system seems to be unquestionable. Both will contribute to changes monitored in the adult brain after manipulation in early life. Neither seems to be a likely explanation for the forms of functional plasticity described in the studies of Merzenich, Kaas, and their colleagues (see Kaas et al., 1983, for a summary). 
Finally, the results of both partial SmI cortex removal and selective whisker deafferentation in neonates suggest that the detailed arrangement of peripheral projections to a central target are not specified genetically. In an earlier paper, it was proposed that the qualitative and quantitative organization of the periphery, under genetic control, might be sufficient to account for the pattern and size of central structures related to that periphery (Woolsey, 1978). The present results suggest that epigenetic mechanisms are not at play to adjust the size of a central target. Thus, structures that are significantly attenuated, as the visual cortex of the mole (Allison and Van Twyer, 1970), or expanded, as the auditory cortex of the bat (Suga, 1984), for example, may have arisen by selection for several mutations affecting the relevant portions of the pathways involved.

\section{References}

Allison, T., and H. Van Twyer (1970) Sensory representation in the neocortex of the mole, Scalopus aquaticus. Exp. Neurol. 27: 554-563.

Al-Najdi, M. R. (1965) The transfer of antibody from mother to foetus in the guinea pig. Thesis, University of Leeds, UK.

Arvidsson, J. (1982) Somatotopic organization of vibrissal afferents in the trigeminal sensory nuclei of the rat studied by transganglionic transport of HRP. J. Comp. Neurol. 211: 84-92.

Azmitia, E. C., A. M. Buchan, and J. H. Williams (1978) Structural and functional restoration by collateral sprouting of hippocampal 5HT axons. Nature 274: 374-376.

Barnes, J. M. (1959) Antitoxin transfer from mother to foetus in the guinea pig. J. Pathol. Bacteriol. 77: 371-380.

Belford, G. K., and H. P. Killackey (1979) The development of vibrissae representation in subcortical trigeminal centers of the neonatal rat. J. Comp. Neurol. 188: 63-74.

Belford, G. R., and H. P. Killackey (1980) The sensitive period in the development of the trigeminal system of the neonatal rat. J. Comp. Neurol. 193: 335-350.

Bennett, M. R., and A. G. Pettigrew (1974) The formation of synapses on striated muscle during development. J. Physiol. (Lond.) 241: 515545 .

Brambell, F. W. R. (1970) The transmission of passive immunity from mother to young. In Frontiers of Biology, Vol. 18, F. W. R. Brambell, ed., American Elsevier, New York.

Brown, M. C., and R. Ironton (1978) Sprouting and regression of neuromuscular synapses in partially denervated muscles. J. Physiol. (Lond.) 278: 325-348.

Brown, M. C., J. K. S. Jansen, and D. Van Essen (1976) Polyneuronal innervation of skeletal muscle in newborn rats and its elimination during maturation. J. Physiol. (Lond.) 261: 387-422.

Clarke, P. G. H., and W. M. Cowan (1975) Ectopic neurons and aherrant connections during neural development. Proc. Natl. Acad. Sci. USA 72: 4455-4458.

Courtney, K., and S. Roper (1976) Sprouting of synapses after partial denervation of frog cardiac ganglion. Nature 259: 317-319.

Davies, A., and A. Lumsden (1984) Relation of target encounter and neuronal death to nerve growth factor responsiveness in the developing mouse trigeminal ganglion. J. Comp. Neurol. 223: 124-137.

Devor, M., D. Schonfeld, Z. Zeltzer, and P. D. Wall (1979) Two modes of cutaneous reinnervation following peripheral nerve injury. J. Comp. Neurol. 185: 211-220.

Diamond, J. (1982) The patterning of neuronal connections. Am. Zool. 22: $153-172$.

Dun, R. B. (1959) The development and growth of vibrissae in the house mouse with particular reference to the time of action on the tabby (Ta) and ragged (Ra) genes. Aust. J. Biol. Sci. 12: 312-330.

Durham, D., and T. A. Woolsey (1984) Effects of neonatal whisker lesions on mouse central trigeminal pathways. J. Comp. Neurol. 223: 424-447.

Edds, M. V. (1953) Collateral nerve regeneration. Q. Rev. Biol. 28: 260-276.

Emmers, R. (1965) Organization of the first and second somesthetic regions (SI and SII) in the rat thalamus. J. Comp. Neurol. 124: 214228.

Erzurumlu, R. S., and H. P. Killackey (1983) Development of order in the rat trigeminal system. J. Comp. Neurol. 213: 365-380.
Fenton, E. L. (1970) Tissue culture assay of nerve growth factor and specific antiserum. Exp. Cell Res. 59: 383-392.

Friede, R. L. (1960) A comparative study of cytoarchitectonics and chemoarchitectonics of the cerebral cortex of the guinea pig. Z. Zellforsch. 52: 482-493.

Fujisawa, H. (1984) Mode of axonal growth in developing and regenerating retinotectal projection. In Neuronal Growth and Plasticity, M. Kuno, ed., pp. 259-270, Japan Science Society Press, Tokyo.

Gorin, P. D., and E. M. Johnson (1979) Experimental autoimmune model of nerve growth factor deprivation: Effect on developing peripheral sympathetic and sensory neurons. Proc. Natl. Acad. Sci. USA 76: 5382-5386.

Greene, L. A. (1977) Quantitative in vitro studies on the nerve growth factor (NGF) requirement of neurons: II. Sensory neurons. Dev. Biol. 58: $106-113$.

Guillery, R. W. (1972) Binocular competition in the control of geniculate cell growth. J. Comp. Neurol. 144: 117-130.

Hoffman, H. (1952) Acceleration and retardation of the process of axon sprouting in partially denervated muscles. Aust. J. Exp. Biol. Med. Sci. 30: 541-566.

Hulsebosch, C. E., R. E. Coggeshall, and J. R. Perez-Polo (1984) Effects of nerve growth factor and its antibodies on sprouting of sensory axons following spinal cord hemisection. Brain Res. 323: 1-10.

Ito, M., and M. L. Seo (1983) Avoidance of neonatal cortical lesions by developing somatosensory barrels. Nature 301:600-602.

Ivy, G. O., and H. P. Killackey (1982) Ephemeral cellular segmentation in the thalamus of the neonatal rat. Dev. Brain Res. 2: 1-17.

Jackson, P. C., and J. Diamond (1984) Temporal and spatial constraints on the collateral sprouting of low threshold mechanosensory nerves in the skin of rats. J. Comp. Neurol. 226: 336-345.

Jacquin, M. F., and R. W. Rhoades (1983) Central projections of the normal and "regenerate" infraorbital nerve in adult rats subjected to neonatal unilateral infraorbital lesions: A transganglionic horseradish peroxidase study. Brain Res. 269: 137-144.

Jeanmonod, D., F. L. Rice, and H. Van der Loos (1977) Mouse somatosensory cortex: Development of the alterations in the barrel field which are caused by injury to the vibrissal follicles. Neurosci. Lett. 6: $151-156$

Jeanmonod, D., F. L. Rice, and H. Van der Loos (1981) Mouse somatosensory cortex: Alterations in the barrelfield following receptor injury at different early postnatal ages. Neuroscience 6: 1503-1535.

Johnson, E. M., P. D. Gorin, L. D. Brandeis, and J. Pearson (1980) Dorsal root ganglion neurons are destroyed by exposure in utero to maternal antibody to nerve growth factor. Science 210:916-918.

Johnson, E. M., P. D. Gorin, P. A. Osborne, R. E. Rydel, and J. Pearson (1982) Effects of autoimmune NGF deprivation in the adult rabbit and offspring. Brain Res. 240: 131-140.

Johnson, E. M., P. A. Osborne, R. E. Rydel, R. E. Schmidt, and J. Pearson (1983) Characterization of the effects of autoimmune nerve growth factor deprivation in the developing guinea pig. Neuroscience 8: 631-642.

Kaas, J. H., M. M. Merzenich, and H. P. Killackey (1983) The reorganization of somatosensory cortex following peripheral nerve damage in adult and developing mammals. Annu. Rev. Neurosci. 6: 325-356.

Killackey, H. P., G. R. Belford, R. Ryugo, and D. K. Ryugo (1976) Anomalous organization of thalmocortical projections consequent to vibrissae removal in the newborn rat and mouse. Brain Res. 104: 309-315.

Konigsmark, B. W. (1970) Methods for the counting of neurons. In Contemporary Research Methods in Neuroanatomy, W. H. Nauta and S. O. E. Ebbesson, eds., pp. 315-380, Springer-Verlag, New York.

Lee, K. J., and T. A. Woolsey (1975) A proportional relationship between peripheral innervation density and cortical neuron number in the somatosensory system of the mouse. Brain Res. 99: 349-353.

Leissring, J. C., and J. W. Anderson (1961) The transfer of serum proteins from mother to young in the guinea pig: I. Prenatal rates and routes. Am. J. Anat. 109:149-156.

Levi-Montacini, R., H. Meyer, and V. Hamburger (1954) In vitro experiments on the effects of mouse sarcomas 180 and 37 on the spinal and sympathetic ganglia of the chick embryo. Cancer Res. 14: 49-57.

Lichtman, J. W. (1977) The reorganization of synaptic connections in the rat submandibular ganglion during postnatal development. J. Physiol. (Lond.) 273: 155-177. 
Lichtman, J. W., and D. Purves (1980) The elimination of redundant pre-ganglionic innervation to hamster sympathetic ganglion cells in early postnatal life. J. Physiol. (Lond.) 301: 213-228.

Liu, C. N., and W. W. Chambers (1958) Intraspinal sprouting of dorsal root axons. A. M. A. Arch. Neurol. Psychiatry 79: 46-61.

Luna, L. G. (1968) Manual of Histologic Staining Methods of the Armed Forces Institute of Pathology, McGraw-Hill, New York.

Ma, P. K. M., and T. A. Woolsey (1984) Cytoarchitectonic correlates of the vibrissae in the medullary trigeminal complex of the mouse. Brain Res. 306: 374-379.

Murray, J. G., and J. W. Thompson (1957) The occurrence and function of collateral sprouting in the sympathetic system of the cat. $J$. Physiol. (Lond.) 135: 133-162.

Nachlas, M. M., K.-C. Tsou, E. DeSouza, C.-S. Cheng, and A. M. Seligman (1957) Cytochemical demonstration of succinic dehydrogenase by the use of a new p-nitrophenyl substituted ditetrazole. J. Histochem. Cytochem. 5: 420-436.

Nagy, J. I., S. R. Vincent, W. A. Staines, H. C. Fibiger, T. D. Reisine, and H. I. Yamamura (1980) Neurotoxic action of capsaicin on spinal substance $P$ neurons. Brain Res. 186: 435-444.

O'Leary, D. D. M., and W. M. Cowan (1982) Further studies on the development of the isthmo-optic nucleus with special reference to the occurrence and fate of ectopic and ipsilaterally projecting neurons. J. Comp. Neurol. 212: 399-416.

O'Leary, D. D. M., B. B. Stanfield, and W. M. Cowan (1981) Evidence that the early postnatal restriction of the cells of origin of the callosal projection is due to the elimination of axonal collaterals rather than the death of neurons. Dev. Brain Res. 1: 607-617.

Pearson, J., E. M. Johnson, and L. Brandeis (1983) Effects of antibodies to nerve growth factor on intrauterine development of derivatives of cranial neural crest and placode in the guinea pig. Dev. Biol. 96: 3236.

Peters, V. B., and L. B. Flexner (1950) Biochemical and physiological differentiation during morphogenesis: VIII. Quantitative morphologic studies on the developing cerebral cortex of the fetal guinea pig. Am. J. Anat. 86: 133-162.

Pidoux, B., R. Verley, E. Farkas, and J. Scherrer (1979) Projections of the common fur of the muzzle upon the cortical area for mystical vibrissae in rats dewhiskered since birth. Neurosci. Lett. 11:301306.

Purves, D., and J. W. Lichtman (1980) Elimination of synapses in the developing nervous system. Science 210: 153-157.

Rakic, P. (1977) Prenatal development of the visual system in rhesus monkey. Phil. Trans. R. Soc. London [Biol.] 278: 245-260.

Redfern, R. A. (1970) Neuromuscular transmission in newborn rats. J. Physiol. (Lond.) 209: 701-709.

Rhoades, R. W., J. M. Fiore, M. F. Math, and M. R. Jacquin (1983) Reorganization of trigeminal primary afferents following neonatal infraorbital nerve section in hamster. Dev. Brain Res. 7: 337-342.

Rice, F. L. (1975) The development of the primary somatosensory cortex in the mouse: (1) A Nissl study of the ontogenesis of the barrels and the barrel field, (2) A quantitative autoradiographic study of the time of origin and pattern of migration of neuroblasts in area SI. Doctoral dissertation, Johns Hopkins University, Baltimore, Maryland, University Microfilms, Inc., Ann Arbor, MI.

Rice, F. L. (1983) A comparative analysis of barrel and lamina formation in SI cortex of small mammals. Anat. Rec. 205: 161A-162A (Abstr.).

Rice, F. L., and H. Van der Loos (1977) Development of the barrels and barrel field in the somatosensory cortex of the mouse. J. Comp. Neurol. 171: 545-560.

Rubin, J. S., and R. A. Bradshaw (1981) Isolation of partial amino acid sequence analysis of nerve growth factor from the guinea pig prostate. J. Neurosci. Res. 6: 451-464.

Rugh, R. (1968) The Mouse: Its Reproduction and Development, Burgess, Minneapolis, MN.

Savy, C., S. Margules, E. Farkas-Bargeton, and R. Verley (1981) A morphometric study of mouse trigeminal ganglion after unilateral destruction of vibrissae follicles at birth. Brain Res. 217: 265-277.

Scott, J. P. (1953) The embryology of the guinea pig. Am. J. Anat. 60: 397-432.

Simons, D. J. (1978) Response properties of vibrissae units in rat SI somatosensory neocortex. J. Neurophysiol. 41: 798-820.

Simons, D. J., and T. A. Woolsey (1979) Functional organization in mouse barrel cortex. Brain Res. 165: 327-332.
Simons, D. J., D. Durham, and T. A. Woolsey (1984) Functional organization of mouse and rat SmI barrel cortex following vibrissal damage on different postnatal days. Somatosens. Res. 1: 207-245.

Smith, C. L. (1983) The development and postnatal organization of primary afferent projections to the rat thoracic spinal cord. J. Comp. Neurol. 220: 29-43.

Smolen, A. J., L. L. Wright, and T. J. Cunningham (1983) Neuron numbers in the superior cervical sympathetic ganglion of the rat: $A$ critical comparison of methods for cell counting. J. Neurocytol. 12: 739-750.

Snedecor, G. W., and W. G. Cochran (1967) Statistical Methods, Iowa State U.P., Ames, IA.

Speidel, C. C. (1941) Adjustments of nerve endings. Harvey Lect. 36: $126-158$.

Speidel, C. C. (1942) Studies of living nerves. VII. Growth adjustments of cutaneous terminal arborizations. J. Comp. Neurol. 76: 57-73.

Stanfield, B. B., and W. M. Cowan (1979) Evidence for sprouting of entorhinal afferents into the hippocampal zone of the molecular layer of the dentate gyrus. Anat. Embryol. 165: 27-52.

Stanfield, B. B., D. D. M. O'Leary, and C. Fricks (1982) Selective collateral elimination in early postnatal development restricts cortical distribution of rat pyramidal tract neurones. Nature 298: 371-373.

Steward, O., C. Cotman, and G. Lynch (1976) Quantitative autoradiographic and electrophysiological study of reinnervation of dentate gyrus by contralateral entorhinal cortex following ipsilateral entorhinal lesions. Brain Res. 114: 181-200.

Suga, N. (1984) Neural mechanisms of complex-sound processing for echolocations. Trends Neurosci. 7: 20-27.

Thanos, S., and F. Bonhoeffer (1983) Investigations on the development and topographic order of retinotectal axons: Anterograde and retrograde staining of axons and perikarya with rhodamine in vivo. J. Comp. Neurol. 219: 420-430.

Ungewitter, L. H. (1951) A silver nitrate method for nerve fibers and nerve endings. Stain Technol. 26: 73-76.

Van der Loos, H. (1976) Barreloids in mouse somatosensory thalamus. Neurosci. Lett. 2: 1-6.

Varon, S., C. Raiborn, and E. Tyszka (1973) In vitro studies of dissociated cells from newborn mouse dorsal root ganglia. Brain Res. 54: 51-63.

Verley, R., and I. Onnen (1981) Somatotopic organization of the tactile thalamus in normal adult and developing mice and in adult mice dewhiskered since birth. Exp. Neurol. 72: 462-474.

Waite, P. M. E. (1973) Somatotopic organization of vibrissal responses in the ventrobasal complex of the rat thalamus. J. Physiol. (Lond.) 228: $527-540$.

Waite, P. M. E., and B. G. Cragg (1982) The peripheral and central changes resulting from cutting or crushing the afferent nerve supply to the whiskers. Proc. R. Soc. [Lond.] 214: 191-211.

Waite, P. M. E., and P. K. Taylor (1978) Removal of whiskers in young rats causes functional changes in cerebral cortex. Nature 274: 600-602.

Wall, P. D., M. Fitzgerald, J. C. Nussbaumer, H. Van der Loos, and M. Devor (1982) Somatotopic maps are disorganized in adult rodents treated neonatally with capsaicin. Nature 295: 691-693.

Weddell, G., L. Guttmann, and E. Guttmann (1941) The local extension of nerve fibres into denervated areas of skin. J. Neurol. Neurosurg. Psychiatry 4: 206-255.

Welker, C. (1976) Receptive fields of barrels in the somatosensory neocortex of the rat. J. Comp. Neurol. 166: 173-190.

Weller, W. L., and J. I. Johnson (1975) Barrels in cerebral cortex altered by receptor disruption in newborn, but not in five day old mice (Cricetidae and Muridae). Brain Res. 83: 504-508.

Wong-Riley, M. T. T., and C. Welt (1980) Histochemical changes in cytochrome oxidase of cortical barrels after vibrissal removal in neonatal and adult mice. Proc. Natl. Acad. Sci. USA 77: 2333-2337.

Woolsey, T. A. (1978) Some anatomical bases of cortical somatotopic organization. Brain Behav. Evol. 15: 325-371.

Woolsey, T. A. (1984) The postnatal development and plasticity of the somatosensory system. In Neuronal Growth and Plasticity, M. Kuno, ed., pp. 241-257, Japan Science Society Press, Tokyo, Japan.

Woolscy, T. A., and M. L. Dicrker (1982) Morphometric approaches to neuroanatomy with emphasis on computer-assisted techniques. In Cytochemical Methods in Neuroanatomy, V. Chan-Palay and S. L. Palay, eds., pp. 69-91, Alan R. Liss, New York.

Woolsey, T. A., and H. Van der Loos (1970) The structural organi- 
zation of layer IV in the somatosensory region (SmI) of mouse cerebral cortex. Brain Res. 17: 205-242.

Woolsey, T. A., and J. R. Wann (1976) Areal changes in mouse cortical barrels following vibrissal damage at different postnatal ages. J. Comp. Neurol. 170: 53-66.

Woolsey, T. A., C. Welker, and R. H. Schwartz (1975) Comparative anatomical studies of the SmI face cortex with special reference to the occurrence of "barrels" in layer IV. J. Comp. Neurol. 164: 7994.

Woolsey, T. A., J. R. Anderson, J. R. Wann, and B. B. Stanfield (1979) The effects of early vibrissae damage on neurons in the ventrobasal (VB) thalamus of the mouse. J. Comp. Neurol. 184: 363-380.

Woolsey, T. A., D. Durham, R. M. Harris, D. J. Simons, and K. L.
Valentino (1981) Somatosensory development. In Development of Perception: Psychobiological Perspectives, Vol. 1, R. N. Aslin, J. R. Alberts, and M. R. Peterson, eds., pp. 259-292, Academic, New York. Yamakato, M., and T. Yohro (1979) Subdivision of mouse vibrissae on an embryological basis with descriptions of variations in the number and arrangement of sinus hairs and cortical barrels in BALB/C $(\mathrm{nu} /+)$, nude $(\mathrm{nu} / \mathrm{nu})$ and hairless $(\mathrm{hr} / \mathrm{hr})$ strains. Am. J. Anat. 155: 153-174.

Zeigler, H. P. (1964) Cortical sensory and motor areas of the guinea pig (Cavia Porcellus). Arch. Ital. Biol. 102: 587-598.

Zucker, E., and W. I. Welker (1969) Coding of somatic sensory input by vibrissae neurons in the rat's trigeminal ganglion. Brain Res. 12: $138-156$ 